\title{
Recuperação de áreas degradadas por mineração: uma revisão de métodos recomendados para garimpos
}

\author{
Isis Arend da SILVA ${ }^{1}$, Adriana Rosa CAMPAGNA ${ }^{2}$ \& Kátia Helena LIPP-NISSINEN ${ }^{1}$
}

\begin{abstract}
Departamento de Pesquisa e Análises Laboratoriais, Fundação Estadual de Proteção Ambiental Henrique Luis Roessler. Av. Borges de Medeiros, 261, 10º andar, CEP 90020-021, Porto Alegre, RS, Brasil (isisarend@gmail.com; katiahln@fepam. rs.gov.br).

2 Departamento de Controle, Fundação Estadual de Proteção Ambiental Henrique Luis Roessler. Av. Borges de Medeiros, 261, 9o andar, CEP 90020-021, Porto Alegre, RS, Brasil (adriana-campagna@fepam.rs.gov.br).
\end{abstract}

Silva, I. A. da., Campagna, A. R. \& Lipp-Nissinen, K. H. 2018. Recuperação de áreas degradadas por mineração: uma revisão de métodos recomendados para garimpos. Pesquisas em Geociências, 45: e0691.

DOI: https://doi.org/10.22456/1807-9806.91386

Resumo. Empreendimentos de mineração, como a extração de ágata no Rio Grande Sul (RS), geram impactos ambientais e, por obrigação legal, as áreas degradadas devem ser recuperadas. 0 Plano de Recuperação de Áreas Degradadas (PRAD) é o instrumento que visa qualificar os projetos, porém, nem sempre é suficientemente detalhado quanto às metodologias a serem empregadas. 0 presente artigo revisa e discute as mais apropriadas técnicas de bioengenharia empregadas em processos de Recuperação de Área Degradada (RAD) globalmente, com ênfase na aplicação em garimpos. Métodos eficazes para remodelamento e estabilidade do relevo, drenagem, manejo de solo, e oportunidades de reaproveitamento de rejeitos são indicados. Estratégias para a seleção de plantas e técnicas de plantio são comparadas. Em todos os casos, são priorizadas alternativas viáveis sob os aspectos ambientais e econômicos. Resultados mais satisfatórios são oriundos da restauração ecológica, uma prática de revegetação atualmente em expansão. A Análise Funcional de Ecossistema/Paisagem (EFA) é a metodologia recomendada para um monitoramento mais abrangente do processo. A inclusão do PRAD desde o planejamento inicial da mina reverterá no sucesso da recuperação. Este estudo poderá contribuir para a minimização de impactos e passivos, norteando, por exemplo, a elaboração de termos de referência para PRAD no licenciamento ambiental da mineração por garimpo.

Palavras-chave. Ágata, bioengenharia, licenciamento ambiental, planos de recuperação de áreas, restauração ecológica, termos de referência.

Abstract. Mine ReHABILITATION: A REVIEW OF RECOMMENDED METHOdS For GARIMPo. Mining projects, such as the extraction of agate in Rio Grande do Sul (RS), generate environmental impacts and, for legal obligation, degraded areas must be rehabilitated. The Degraded Areas Rehabilitation Plan (PRAD) is the instrument that aims to qualify the projects, however it is not always sufficiently detailed as to the methodologies to be used. This paper reviews and discusses the most appropriate bioengineering techniques currently employed in the Degraded Area Rehabilitation (RAD) processes globally, with emphasis on the application in stone mining by 'garimpo' digging. Effective methods for slope re-shaping and stability, drainage system, soil management and stone tailings' reuse opportunities are indicated. Plant selection strategies and planting techniques are compared. In all cases, environmental and economically feasible alternatives are prioritized. The best results come from "ecological restoration", an effective and ever-expanding revegetation practice. The Ecosystem/Landscape Function Analyses (EFA) is the recommended methodology for a broader process monitoring. The inclusion of PRAD in the initial planning of the mine will revert into its rehabilitating success. This study may contribute towards the minimization of liabilities, for example, by guiding the establishment of terms of reference for PRAD during the licensing of 'garimpo' mining. Keywords. Agate, bioengineering, environmental licensing, ecologic restoration, recovery plans, terms of reference. 


\section{Introdução}

A mineração, uma atividade de grande importância econômica, é com frequência altamente impactante ao meio ambiente. Segundo Mechi \& Sanches (2010) e United States Environmental Protection Agency (USEPA, 2011), essa atividade geralmente resulta em desmatamento, poluição hídrica, poluição sonora, subsidências do terreno, assoreamento de rios, impactos visuais, paisagísticos e sobre fauna e flora. De acordo com Brandt Meio Ambiente (BMA, 2001, pg. 5), o garimpo a céu aberto, em especial, é uma forma rudimentar de mineração caracterizada "[...] pela falta de conhecimento do jazimento e pela falta de planejamento, de recursos técnicos e financeiros (geralmente)". Particularmente, isso se dá nos frequentes casos de extração realizada sem planejamento e/ou até de forma ilegal (Heemann, 2005). Esse quadro tem reflexos na capacidade de desenvolvimento de uma boa avaliação dos impactos ambientais da atividade ou mesmo de projetos de controle e de recuperação ambiental da área, previstos na legislação (BMA, 2001). Com frequência, também repercute na interdição de minas em atividade (Endruweit, 2010; Jusbrasil, 2011) e no abandono de outras sem qualquer recuperação, uma vez que esta, comumente, não é realizada concomitantemente à lavra. Tais comportamentos não são exclusivos à mineração de garimpo. Em parte, ocorrem porque no Brasil o Plano de Recuperação de Área Degradada (PRAD) não possui, obrigatoriamente, uma determinação quanto à prospecção de custos e medidas de garantia financeira para cobrir as despesas da fase de encerramento das atividades nos casos de abandono da mina (Roberts et al., 2000; Araújo, 2016).

Por seus impactos, muitas vezes irreversíveis, a mineração é a única atividade cuja obrigação de Recuperação de Áreas Degradadas (RAD) é imposta pela Constituição Federal do Brasil de 1988 (Farias, 2016). O Instituto Chico Mendes de Conservação da Biodiversidade (ICMBIO), em sua Instrução Normativa ${ }^{\circ} 11$ de 2014, uma das quais regulamentam o RAD no Brasil, considera área degradada como "aquela impossibilitada de retornar por uma trajetória natural a um ecossistema que se assemelhe ao estado inicial, dificilmente sendo restaurada, apenas recuperada". A mesma Norma conceitua recuperação como a "restituição de um ecossistema ou de uma população silvestre degradada a uma condição não degradada, que pode ser diferente de sua condição original". Ainda nos termos da Instrução Normativa ICMBIO nํ11/2014, este processo deve ocorrer através da "condução de regeneração natural”, ou seja, é esperado que a recuperação da área seja estimulada, uma vez que, apesar da regeneração natural ocorrer sem indução humana em certas situações, essa não é uma medida comumente empregada. Concorre para tal, o fato da remoção do solo orgânico dificultar o estabelecimento espontâneo da vegetação, intensificando o processo erosivo, principalmente onde a estocagem do solo não foi realizada devidamente (USEPA, 1972; Ferretti, 2002a).

Esse contexto é exemplificado no município de Salto do Jacuí, Rio Grande do Sul (RS), atualmente um dos principais fornecedores de ágata do país e onde a exploração ocorre na forma de garimpos (Batisti \& Tatsch, 2012), localizados geralmente nas proximidades de corpos d'água, lavrados a céu aberto de forma semimecanizada (Heemann, 2005). Os principais impactos da atividade estão relacionados aos processos erosivos decorrentes do relevo modelado em taludes e à contenção inadequada dos estéreis (Heemann et al., 1998). Esses últimos são fonte de erosão intensa, resultando na turbidez e no assoreamento dos corpos d'água (Heemann et al., 1999). Para essas áreas, onde a camada de solo fértil foi removida, medidas onerosas são necessárias para o reajuste do terreno e sua revegetação. Do contrário, resultarão extensas áreas abandonadas (USEPA, 1972). Assim, a busca por formas alternativas para a adequada recuperação destes ambientes é uma necessidade de inegável importância econômica e ambiental, com vistas à continuidade sustentável das atividades.

Em face do exposto, objetiva-se com este estudo revisar as principais metodologias hoje utilizadas em RAD, avaliando comparativamente e indicando as mais adequadas dentre aquelas recomendadas por diferentes autores da literatura nacional e internacional, bem como as dispostas nas normas legais. 0 estudo poderá guiar a elaboração de PRAD, a serem utilizados, em programas de RAD por mineração de pedras preciosas e de 
outros minerais. Objetivou-se identificar técnicas construtivas e de revegetação - mínimas, obrigatórias e/ou alternativas efetivas, para o sucesso de um processo de recuperação.

\section{Bases normativas da recuperação de áreas degradadas por mineração}

0 primeiro marco regulatório para RAD no Brasil está disposto na Constituição Federal: "Aquele que explorar recursos minerais fica obrigado a recuperar o meio ambiente degradado, de acordo com solução técnica exigida pelo órgão público competente, na forma da lei" (Brasil, 1988, art. 225, parágrafo segundo do capítulo VI). 0 Decreto Lei no 97.632 de 1989 (Brasil, 1989) dispõe sobre o objetivo da recuperação, que deve ser a obtenção de estabilidade do meio ambiente. Normalmente, fica exigido ao empreendedor o retorno da área a um estado próximo ao original. Todavia, é o empreendedor quem propõe o aproveitamento futuro da área, de acordo com as possibilidades de uso do solo (Neri \& Sánchez, 2012; Farias, 2016). Em nível federal, a Instrução Normativa ICMBIO $\mathrm{n}^{\circ} 11$ de 2014 estabelece os principais procedimentos para elaboração de um PRAD, documento que acompanha o Estudo de Impacto Ambiental no licenciamento exigido pelo Órgão Federal Ambiental, o Instituto Brasileiro do Meio Ambiente e dos Recursos Naturais Renováveis (IBAMA), com o objetivo de planejamento da recuperação da área, durante e no período pós-operação da mina. No Rio Grande do Sul, as diretrizes são dadas pelo Termo de Referência (TR) para Elaboração do PRAD, da Fundação Estadual de Proteção Ambiental Henrique Luis Roessler (FEPAM, 2012a). Também existem exigências específicas por parte do Departamento Nacional de Produção Mineral (DNPM. NRM- 21, 2002). Há ainda a NBR 13030 de 1999, da Associação Brasileira de Normas Técnicas (ABNT), que requer a adoção de um local de referência no PRAD, permitindo o estabelecimento das metas (Tongway \& Hindley, 2004; International Council on Mining \& Metals - ICMM, 2006). Fora do âmbito estritamente legal, o Ministério do Interior (MINTER) e o IBAMA elaboraram um manual (MINTER \& IBAMA,1990), contendo as principais etapas de um PRAD para mineração e com recomendação de técnicas, que estão incluídas na presente revisão.

A efetividade da recuperação de área depende da execução de todas as etapas do processo. 0 primeiro passo é a estabilização do relevo, do qual depende a revegetação (MINTER \& IBAMA, 1990; Tasmania, 1999; USEPA, 2011). O DNPM, através da NRM - 21/2002, também estabelece o desenvolvimento de um programa de monitoramento da área. Entretanto, a inadequada preparação da área é, com frequência, a razão das falhas dos projetos de RAD (Alberta Agriculture, Food and Rural Development - AAFRD, 2001; ICMM, 2006).

No conjunto da legislação ambiental-minerária brasileira existem várias orientações legais quanto aos objetivos, implantação de estruturas e remodelação de áreas degradadas, contudo sem indicação de métodos ou tecnologias específicas apropriadas. Quanto às estruturas de uso indispensável no processo de recuperação de áreas, também não são encontradas determinações construtivas mínimas (Araújo, 2016). Ou seja, as diretrizes atualmente disponibilizadas pelas autoridades normalizadoras são de caráter geral. Esse fato pode acarretar em equívocos na escolha e na instalação de estruturas, que divergem ao seu propósito.

Embora se verifique uma carência na divulgação e no detalhamento de métodos mais específicos para a minimização dos impactos da mineração, tanto na legislação vigente, quanto em materiais informativos, a especificação do tipo de manejo de cada etapa do processo de recuperação tem sido exigida para o licenciamento ambiental (Marcus, 1997; BMA, 2001; FEPAM, 2012b). Similarmente, um manejo diferenciado durante a operação da mina é necessário para uma maior eficácia no seu fechamento e recuperação. Técnicas de bioengenharia, utilizando consorciação entre elementos biologicamente ativos, como vegetação, e elementos inertes, como concreto e madeira estão cotados em, aproximadamente, um terço do valor total de implantação do RAD, comparativamente ao uso de métodos tradicionais (Pereira, 2001; Moretto, 2012). Isso indica que a consorciação entre os métodos aqui citados seja uma prática econômica, efetiva e, portanto, mais indicada. No termo de referência para elaboração do PRAD é esperada a apresentação de um referencial biblio- 
gráfico e o detalhamento das estruturas eficazes escolhidas para a estabilização biotécnica. $\mathrm{Na}$ inviabilidade de se dispor dessa informação, é ideal que, previamente, sejam realizados testes avaliativos com diversos materiais e estruturas no local a ser recuperado. Ainda, deve-se considerar a possibilidade de novas adequações em virtude de se tratar de métodos cuja eficiência somente poderá ser aferida com o passar do tempo, pois dependem do estabelecimento da vegetação.

Visando o fechamento da mina, a empresa, ou o seu responsável local, deve obter da FEPAM a desoneração de passivo ambiental. Junto ao DNPM deverá requerer a renúncia ao título minerário, comprovando o cumprimento de todas as determinações normativas (Luz \& Sampaio, 2015; Araújo, 2016).

\section{Resultados: métodos de RAD por mineração a céu aberto de pedras preciosas e afins}

Nas próximas seções é apresentado um rol de procedimentos para RAD, obtidos a partir da literatura internacional atual, com destaque para as opções técnicas de maior relevância.

\subsection{Ajuste de Relevo}

0 ajuste de relevo tem como principais funções a estabilização do solo, voltada para o controle da erosão, e a aderência da vegetação. Consiste na adequação do relevo à paisagem e na instalação de estruturas para evitar o deslocamento das partículas sólidas provenientes do solo exposto. As principais medidas para o garimpo de pedras preciosas consistem no remodelamento dos taludes para obtenção de estabilidade geotécnica, no controle de drenagem e no aumento da capacidade de infiltração do solo (USEPA, 2011; Neri \& Sánchez, 2012; British Columbia - BC, 2012). A seguir estão descritas propostas recomendadas para o ajuste de relevo.

\subsubsection{Remodelamento e manejo de taludes}

Em vista das variações de geomorfologia de cada região, não são verificados na literatura indicadores genéricos para altura e ângulo mais apropriados à configuração dos taludes. A inclinação adequada depende dos parâmetros do maciço, material mineral, sendo esta uma avaliação geotécnica. Segundo Brito (2011), a instabilidade em taludes de mineração é aceitável, desde que os riscos sobre o pessoal e equipamentos sejam controláveis. Para esse autor, a definição da inclinação de um talude é uma disputa entre segurança e economia. Quanto à altura dos taludes, as dimensões máximas indicadas para o uso em garimpo de pedras preciosas a céu aberto são de 5 $\mathrm{m}$ de altura por $3 \mathrm{~m}$ de largura de berma, de acordo com Tasmania (1999) e Heemann et al. (1999), evitando-se alturas superiores a $15 \mathrm{~m}$ para não comprometer a estabilidade (Tasmania, 1999). Conforme recomendação de Minerals Council of Australia (MCA, 1998), a camada superficial do solo deve ser reposta apenas nas faces dos taludes com inclinação igual ou menor a $27 \%$, permitindo a aderência do solo. Uma inclinação máxima de 2:1 (50\%) para aderência do solo e estabilização da vegetação é também sugerida por outros autores (USEPA, 1976; USDA \& USFS, 2006). Se necessária, a gradagem do solo nas faces do talude deve ser executada sempre no sentido horizontal (MCA, 1998; Departamento Nacional de Infra-Estrutura de Transportes - DNIT \& Instituto de Pesquisas Rodoviárias - IPR, 2009). Segundo MCA (1998) e Commonwealth of Australia (COFA, 2006), devese modelar o talude em uma forma côncava, para torná-lo permeável e adequado à redução da velocidade da água. As bermas originadas da reconfiguração do talude conferem estabilização e segurança (Fig. 1). Conforme MINTER \& IBAMA (1990), as bermas devem ser construídas em terrenos com inclinação maior do que 20\%, configurando-os em bancadas. 0 uso dessas estruturas está fundamentado na literatura e é indicado em um relevante número de manuais de práticas de mineração. É recomendado que as bermas sejam inversas, com uma leve inclinação para dentro em direção aos drenos. Essa inclinação não deve ultrapassar $2 \%$ no sentido longitudinal e ao longo da berma de contorno, que pode ser construída com pilhas de pedregulhos oriundos do estéril armazenado. Para Couto et al. (2010) e USEPA (2011), é necessária a construção de barreiras nas faces de talude instáveis para a contenção de sedimentos. Heemann et al. 
(1999) sugerem utilizar estéreis para a sustentação das bancadas superiores das frentes de lavra. Quaisquer materiais soltos e/ou instáveis deverão ser removidos dos taludes (ICMM, 2006; DNIT \& IPR, 2009).

\subsubsection{Instalação e manejo de estruturas de drena-} gem

A instalação de canalizações para drenagem da água e a utilização de técnicas para redução da velocidade do fluxo, são essenciais no processo de RAD conforme apontado e exemplificado por MINTER \& IBAMA (1990) e Highland Engineering (2009), dentre outros vários autores. Muitos tipos de canais de drenagem são propostos para evitar assoreamento e erosão, embora os mais recomendáveis sejam os trapezóides, ou parabólicos (MCA, 1998), construídos com baixo-gradiente para o escoamento hídrico (Heemann et al., 1999) e com drenos de interceptação perpendiculares ao fluxo d'água (MCA, 1997). Já as estruturas de redução de velocidade e o revestimento dos drenos são procedimentos essenciais, atuando no sentido de evitar o assoreamento e a erosão. Os drenos podem ser revestidos com: (a) pedregulhos fixados sem argamassa (enrocamento); (b) pedregulhos fixados com argamassa ("pedras de mão"); (c) geotêxteis revegetados (fibras fixadoras do solo e facilitadoras da revegetação); (d) gabiões (estruturas armadas preenchidas por pedras entre outros); (e) sacos com mistura de solo-cimento e água; (f) concreto (MINTER \& IBAMA, 1990; MCA, 1998).

As bermas de contorno nos taludes, além da facilitar a estabilização, também têm a função estrutural de reduzir a velocidade e evitar o livre deslocamento da água de um talude para o outro. A instalação de drenos de intercepção maximiza esse efeito (MCA, 1997; Tasmania, 1999). Enfatizando ainda o papel dos drenos, DNIT \& IPR (2005) afirmam que a instalação de um sistema de drenagem, por si só, possibilita a estabilidade de taludes, como tem sido verificado ao longo de rodovias.

A instalação de downdrains, ou seja, canos que conduzem a água de um nível para o outro nos taludes sem contato com o solo, também é sugerida (Highland Engineering, 2009). Assim como é a adição de regiões filtradoras, caracterizadas pelo plantio de vegetação no interior dos drenos (Pennsylvania Department of Environmental Pro-

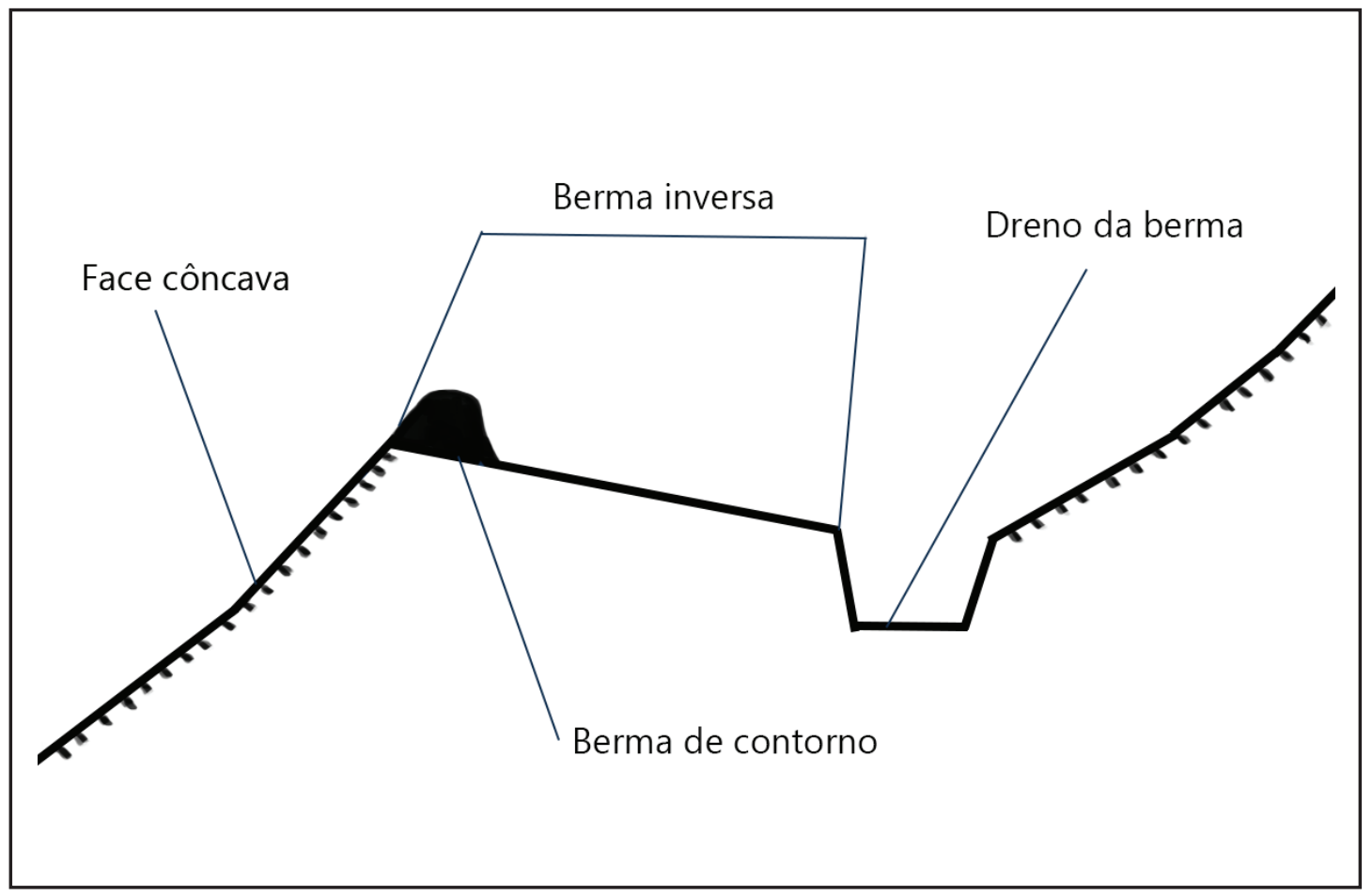

Figura 1. Estruturas de estabilidade de taludes.

Figure1. Slope stability structures. 
tection - PDEP, 2012; Tasmania, 1999). Para PDEP (2012), as regiões filtradoras devem estar recobertas por gramíneas, enquanto Tasmania (1999) sugere que esta região contenha uma vegetação de portes variados. $\mathrm{Na}$ eventual hipótese de se direcionar os drenos diretamente a uma área vegetada, é necessário que o fluxo seja bem distribuído, evitando erosão e alteração das condições naturais da área (PDEP, 2012).

O mais recomendável quanto ao direcionamento do fluxo drenado é que esse seja para uma lagoa sedimentação (Tasmania, 1999). O fluxo pode ser conduzido, posteriormente, para um corpo d'água natural ou infiltrar-se diretamente na região. Se direcionado a um corpo d'água, o volume do escoamento deve ser sempre controlado (MCA, 1998). Ainda, conforme Neri \& Sánchez (2012), a retirada da água deve ser realizada por bombeamento, caso o sentido de escoamento superficial esteja voltado para uma cota mais baixa da mina. Enquanto a manutenção do entorno do sistema de drenagem vegetado com espécies apropriadas também é útil para evitar erosão (USEPA, 1972).

\subsubsection{Instalação e manejo de lagoas de sedimentação}

As lagoas de sedimentação são parte integrante do sistema de drenagem, essenciais para o controle da entrada de partículas sólidas (por exemplo, estéreis) no ambiente aquático do corpo receptor, durante a operação e recuperação do sítio de mineração. As instruções de construção e manejo encontradas são específicas para cada um dos vários tipos diferenciados de lagoas. Essas devem ser projetadas de acordo com as condições hidrológicas da região (Hill, 1996; MCA, 1998).

Conforme destaca Hill (1996), a lagoa deve ser projetada com um formato que facilite a remoção mecânica de sedimentos depositados no seu fundo. Os sedimentos sem contaminantes podem ser usados na recuperação da área degradada, somando-se ao solo disponível.

Idealmente, uma lagoa menor deve ser construída a montante e interligada por um canal à lagoa principal, para remoção parcial das partículas em suspensão. Os seguintes aspectos da lagoa devem ser calculados individualmente para cada projeto: tempo de retenção de volume de sedimentos acumulados, turbulência e correntes, capacidade e fluxo da bacia. 0 preenchimento da lagoa por sedimentos deve ser limitado ao máximo de $50 \%$ de sua profundidade, com 1,5 m de líquido acima do sedimento (Hill, 1996; MCA, 1998). Dentre as medidas construtivas sugeridas para as lagoas de sedimentação, as principais têm como objetivo a redução da velocidade da água, amplificando a capacidade de sedimentação de partículas sólidas. Destaca-se o uso de dispersores nas desembocaduras das lagoas e também no sistema de drenagem, para controlar o volume e a velocidade de saída da água, evitando a erosão nos canais de drenagem e no corpo d'água (Hill, 1996; MCA, 1998; Tasmania, 1999). Outra medida sugerida é o uso de defletores ou chicanas (baffles) no interior das lagoas, que, reduzindo significativamente a velocidade d'água (Shilton \& Harrison, 2003; Sah et al., 2011), impedem o livre fluxo de água na lagoa (Fig. 2A) (Tasmania, 1999). A utilização de vertedouro, do tipo "poço-galeria", também é indicada para evitar erosão do canal de deságue (Fig. 2B) (MCA, 1998). Uma prática comumente observada em garimpos é o acúmulo de água em uma cota mais baixa da mina, a partir da qual essa necessita ser bombeada (Fig. 3) (Neri \& Sánchez, 2012).

Durante a operação da mina, MCA (1998) sugere o reaproveitamento da água na irrigação do plantio realizado para a revegetação, alternativamente ao seu descarte em um corpo d'água receptor. A aspersão controlada em grandes áreas vegetadas, por exemplo, agrícolas ou silvícolas, também pode ser feita, observando-se as condições de qualidade da água, conforme sugerido por USEPA (1976). Contudo, após a operação do garimpo e já nas fases finais de recuperação da área, o uso de uma lagoa de sedimentação é mais indicado. Assim, o acúmulo de água em cotas mais baixas da mina é evitado, diminuindo a necessidade de seu bombeamento periódico. 0 ideal, entretanto, é o preenchimento dessa área mais baixa, para evitar a sua transformação em foco de insetos vetores de doenças (BMA, 2001).

Para o fechamento da mina, a área ocupada pelas lagoas de sedimentação também deve ser recuperada. 


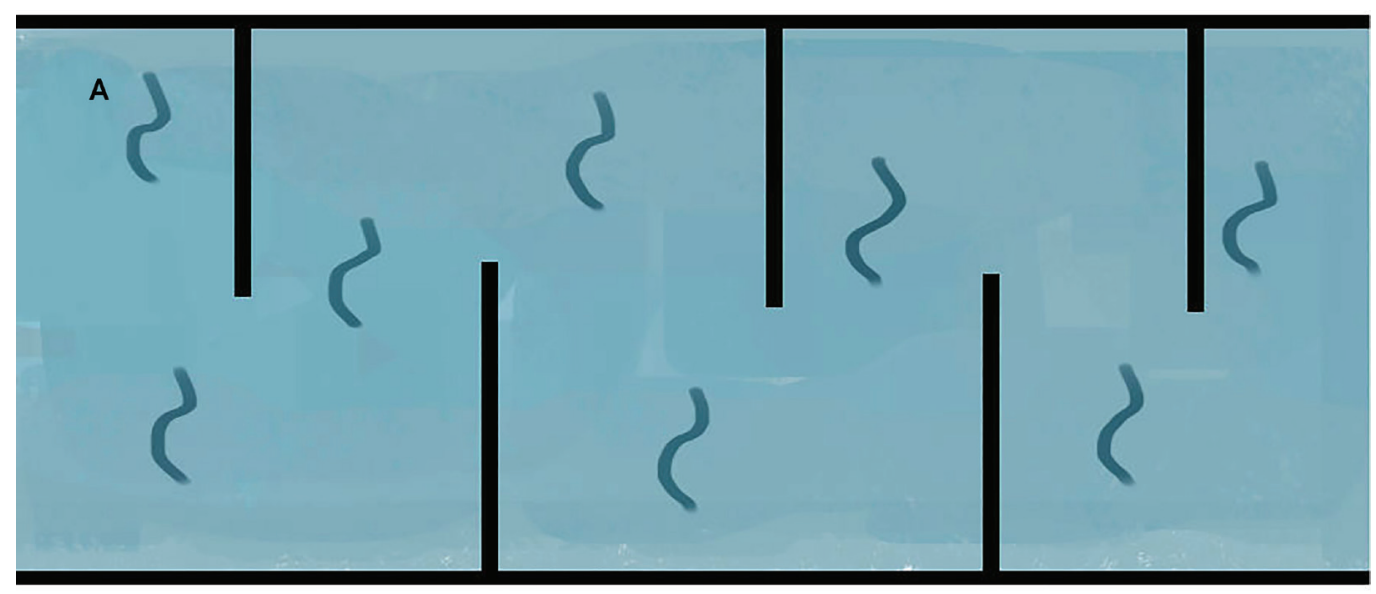

B

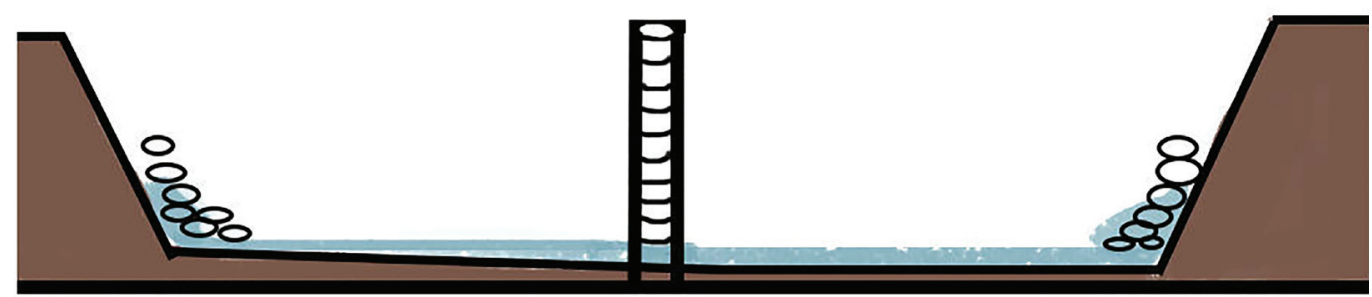

Figura 2. Lagoa de sedimentação. A) Lagoa com chicanas; B) Lagoa com vertedouro.

Figure 2. Sediment pond. A) Pond with baffles; B) Pond with spillway.

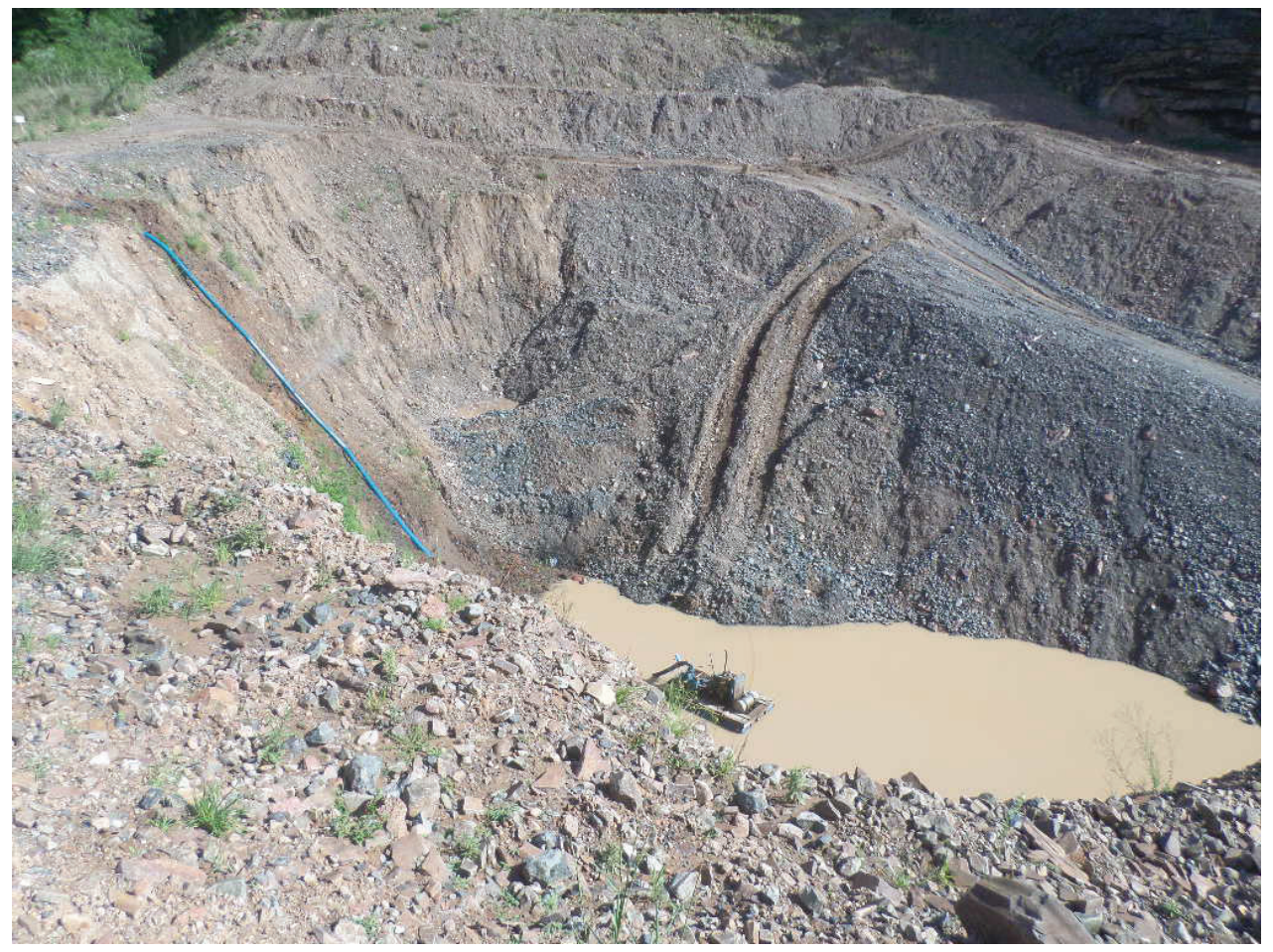

Figura 3. Prática de acúmulo de água na cota mais baixa da mina, observado em Salto do Jacuí, RS.

Figure 3. Common practice of pumping when the runoff flow is directed to the lower quota of the mine, observed in Salto do Jacuí, $R S$. 


\subsubsection{Uso e manejo de estéreis}

O armazenamento do estéril, ou seja, todo o material removido/escavado na extração, separado do solo orgânico, em depósitos denominados "bota-fora" é primordial. Previamente à formação dos depósitos, é preferencial que as obras de drenagem sejam realizadas para a reutilização dos estéreis. Além desse uso, Heemann et al. (1999) indicam a utilização do estéril para a contenção de encostas. Enquanto, segundo MINTER \& IBAMA (1990) e USEPA (2011), a utilização dos estéreis deve ser, preferencialmente, para o preenchimento da cava ou da área lavrada, evitando-se, contudo, a sua compactação.

As pilhas de estéreis não devem ultrapassar a altura natural do relevo local e, de acordo com MCA (1998), a sua extensão deve ser limitada a $50 \mathrm{~m}$ e a declividade a $20^{\circ}$. Para tanto, as pilhas devem ser niveladas e, se sobrecarregadas, transformadas em taludes (COFA, 2006). Sua utilização em sistemas de drenagem dependerá do tipo de material a ser disposto, dos parâmetros geométricos da pilha e da metodologia de construção. No caso de depósitos de substâncias sólidas, o uso de canais periféricos, instalados na base, tem por finalidade desviar a drenagem superficial e conferir estabilidade às pilhas (DNPM. NRM-19, 2002). As descidas d'água, utilizadas conjuntamente às valetas de proteção de corte ou de aterro, recebem a água e a conduzem para bacias de sedimentação ou de amortecimento (Naruna, 2006).

A camada superficial do solo deve ser removida e armazenada no local de formação dos depósitos de estéril, quando esse último não for usado na área no prazo de dois anos (COFA, 2006). Alternativamente, espécies de gramíneas e herbáceas podem ser plantadas sobre os depósitos de estéril (MINTER \& IBAMA, 1990; COFA, 2006), caso esses não sejam reutilizados na operação de recuperação da área. Para agregar-lhes valor, COFA (2006) também sugere transferir os estéreis para uso na construção civil fora do garimpo, já que, na Austrália, sua utilização diretamente na cava e na melhoria do relevo da lavra não é recomendada devido aos altos custos operacionais. A possibilidade de uso dos estéreis no paisagismo também deve ser avaliada (USEPA, 1972).

\subsubsection{Manejo de solo}

O solo é a camada que concentra os nutrientes necessários para o desenvolvimento da vegetação, sendo também um importante banco de sementes (MCA, 1998; Neri \& Sánchez, 2012). Os métodos de remoção e transferência de solo para uso em RAD são de suma importância para a preservação das características da camada superficial do solo e, por isso, devem ser atentamente seguidos. A seguir são apresentados os procedimentos mais recomendados na literatura.

A camada superficial do solo deve ser sempre reposta na área a ser recuperada, mesmo que em uma camada fina. Coletas de solo superficial, em áreas externas ao sítio de exploração, devem ser realizadas em épocas com maior quantidade de sementes disponíveis (COFA, 2006). Segundo MINTER \& IBAMA (1990), o solo removido deve estar acompanhado da vegetação em locais com pastagens naturais ou forrageiras cultivadas. A remoção da camada superficial do solo deve ser feita em duas ou mais etapas. Ou seja, quando a camada a ser recuperada for de 100 a $300 \mathrm{~mm}$, deverá ser removida e recolocada de 50 em $50 \mathrm{~mm}$ para manter a qualidade deste solo e das sementes nele presentes (Tacey \& Glossop, 1980; MCA, 1998). Também se indica a aplicação do solo, preferencialmente, logo após sua remoção para aumentar sua efetividade na área a ser recuperada (MCA, 1998; COFA, 2006). Quando necessário, o armazenamento local das camadas de solo removidas, prévio à mineração, deve ser realizado em pilhas com no máximo $2 \mathrm{~m}$ de altura durante o período de operação (MCA, 1998). Neri \& Sánchez (2012) salientam que na opção de uso do solo armazenado, o manejo dessa camada superficial deve ser feito cuidadosamente para que se garanta a manutenção da sua fertilidade. A reutilização do solo local de maneira adequada reduz os custos e facilita o desenvolvimento daquelas espécies vegetais com maior dificuldade para germinação e crescimento em condições adversas (COFA, 2006). Em casos de baixa disponibilidade da camada superficial do solo, ou quando não tenha sido manejada adequadamente e contenha rejeitos de mineração, Tasmania (1999) sugere a possibilidade de uso de estéreis ou da mistura de solo com outros rejeitos similares. Se limitado, o 
solo também pode ser espalhado horizontalmente em finas camadas ou em linhas (COFA, 2006). Ainda, quando o solo for insuficiente ou indisponível são citadas a coleta e a transferência do solo superficial de áreas externas adjacentes, embora o seu o uso não seja encorajado, pois estas áreas também necessitariam de recuperação (MCA, 1998). Parrotta \& Knowles (2008) demonstraram que a disposição inadequada de solo tem grande influência na composição e desenvolvimento das espécies, resultando em taxas reduzidas de acúmulo de serrapilheira e formação de húmus, necessários para manutenção do ecossistema. Isto significa um retardo no processo de RAD ou no estabelecimento de uma comunidade insustentável, porém, estudos adicionais são necessários. As medidas ressaltadas e os seus resultados justificam a importância fundamental da etapa de planejamento.

A aplicação de argila ou materiais argilosos sobre o solo é recomendada para aumentar o desempenho da vegetação (MINTER \& IBAMA, 1990; Tasmania, 1999). Esta camada pode ser obtida a partir dos resíduos removidos das bacias de sedimentação, de acordo com as características de solo da região (Hill, 1996). Outras medidas incluem a descompactação do solo (MINTER \& IBAMA, 1990; Tasmania, 1999) e o aumento da rugosidade (ICMM, 2006; Australian Government Department of Resources, Energy and Tourism, 2011), por exemplo, através da escarificação de 20 a $30 \mathrm{~cm}$ de profundidade, seguida de gradagem (Bertol, et al., 2006; Silva, 2010). As técnicas de gradagem aumentam a rugosidade e a permeabilidade do solo, incentivando o estabelecimento da vegetação e evitando a erosão resultante de uma superfície compactada e lisa (Aumond \& Maçaneiro, 2014). A gradagem deve ser realizada em toda a área, inclusive horizontalmente na face dos taludes (USEPA, 1972; MCA, 1998). No entanto, essas técnicas mecânicas devem ser evitadas quando o solo estiver muito úmido (MCA, 1998). Além disso, a gradagem deverá ser utilizada com muita cautela para evitar-se a diluição da camada de solo reposta, ou mesmo o aumento da sua compactação (COFA, 2006). 0 uso da subsolagem é uma técnica muito onerosa, enquanto outra opção de mais baixo custo - a aração seguida de grade, não é indicada por favorecer a compactação e os processos de erosão laminar (Lanças, 2002; Silva, 2010). 0 preparo reduzido revolve apenas uma parcela superficial do solo de 20 a $30 \mathrm{~cm}$, propicia o melhor índice de rugosidade e a menor perda de água do solo, sendo a abordagem mais recomendada (Bertol et al., 2006). Enquanto todas as técnicas propostas são dependentes de algum maquinário, é possível realizar a gradagem sem nenhum, apenas se mantendo a largura do distanciamento entre as linhas equivalente à profundidade do corte, como é sugerido por MCA (1998).

\subsubsection{Preparo da área para realização do plantio}

Nesta etapa, será importante cercar a área inicialmente, para evitar a entrada e o pisoteamento por animais de grande porte (Moraes et al., 2013), e protegê-la de queimadas (MINTER \& IBAMA, 1990; Tasmania, 1999). A partir de então, executar as técnicas de preparo do solo cerca de 30 a 40 dias previamente ao plantio (Silva, 2010), como as de descompactação e aumento da rugosidade, $\mathrm{e}$ as demais recomendadas para aumentar o nível de sucesso, apresentadas a seguir.

Estruturas para contenção de sedimentos devem ser utilizadas na área a ser recuperada (Couto et al., 2010; USEPA, 2011; PDEP, 2012). A estabilização química do solo (Highland Engineering, 2009; Moraes et al., 2013) deve ser realizada apenas quando for apontada a sua necessidade, preferencialmente após análises, e idealmente 15 dias antes da aplicação de fertilizantes (DNIT \& IPR, 2009).

A adubação na área a ser recuperada é recomendada para aumentar as chances de estabelecimento e desenvolvimento das plantas (Highland Engineering, 2009; Moraes et al., 2013). Depois do plantio, uma reaplicação de fertilizantes pode ser realizada após quatro a cinco meses (DNIT \& IPR, 2009). Quando a camada superficial do solo for perdida, a adubação deve ser aplicada novamente dentro de um período de um a dois anos, ou até o satisfatório estabelecimento da vegetação. Atentar para a não aplicação de quantidades de fertilizante em excesso (Tasmania, 1999), e sempre verificar a origem e a certificação dos produtos. Uma quantidade maior de fósforo e uma menor de nitrogênio favorecem o crescimento de leguminosas. A apli- 
cação de fertilizantes orgânicos pode aumentar o custo e o nível de dificuldade de aplicação (MCA, 1998), enquanto outros autores sugerem a aplicação de adubo orgânico, como esterco bovino e/ou galináceo, ou torta de mamona, quando disponível no local (DNIT \& IPR, 2009). Para o crescimento de espécies de plantas nativas, os fertilizantes são geralmente administrados em taxas menores geralmente (MCA, 1998). Embora dosagens de fertilizantes sejam sugeridas pelos autores pesquisados, o ideal é o seu cálculo por profissionais da área, através de análise laboratorial do solo e/ou teste em canteiros experimentais.

Apesar das diversas sugestões para o manejo de pragas em áreas a serem recuperadas (Universidade de São Paulo - USP \& Escola Superior de Agricultura - ESALQ 2007; Couto et al., 2010), a utilização de formicidas, pesticidas e substâncias químicas afins deve ser parcimoniosa, estritamente local, evitando-se ao máximo a sua difusão, toxicidade ao meio e impacto sobre demais organismos não-alvo. Deverá ser verificada a procedência e a atual aprovação de uso de quaisquer produtos agrotóxicos pelos órgãos reguladores e de proteção ambiental, em conformidade à legislação estadual, ou municipal se mais restritiva.

As barreiras físicas devem ser instaladas em áreas especiais, como o pé dos taludes e o entorno da zona ripária. Essas precauções impedem que grandes volumes de água de chuva carreguem a vegetação plantada, juntamente com o solo (Couto et al., 2010; USEPA, 2011; PDEP, 2012). Uma opção de barreira é a berma-longa ou bio-log, principalmente para o plantio em zona ripária, visando à estabilização das margens dos cursos d'água (Couto et al., 2010). Ainda é possível, de acordo com PDEP (2012), instalar uma manta vegetal para o plantio das espécies vegetais e também o controle de erosão.

\subsection{Revegetação}

O papel essencial da vegetação para o estabelecimento de um ambiente estável, assim como para o controle da erosão, é citado por vários autores (COFA, 2006; Highland Engineering, 2009, Melo et al., 2013). A partir da realização do ajuste de solo, as espécies vegetais e a forma de condução do plantio determinarão o sucesso ou o fracasso da RAD. As práticas aqui selecionadas estão fundamentadas nos princípios da restauração ecológica. Com o objetivo primário de conter processos erosivos, a restauração ecológica visa recriar comunidades ecologicamente viáveis e estáveis, assistindo e direcionando os processos naturais (Engel \& Parrotta, 2008). A seguir são descritas as propostas recomendadas para o processo de revegetação de áreas degradadas.

\subsubsection{Estabelecimento de áreas prioritárias para o plantio}

A priorização de áreas permite o estabelecimento de estratégias de plantio reduzido e o controle de erosão, principal objetivo durante a primeira fase (MCA, 1998; Tasmania, 1999). Desta forma é possível plantar em uma área menor, utilizando-se a capacidade nucleadora das espécies vegetais. Tasmania (1999) sugere iniciar a revegetação nos taludes superiores. Em sequência, áreas com maiores chances de erosão, como o pé dos taludes e outras áreas acumuladoras de água, devem ser revegetadas (MCA, 1998). Para isso, também é recomendado o plantio na lateral dos canais de drenagem (Hill, 1996).

\subsubsection{Seleção de espécies}

A seleção deve visar espécies de plantas adaptadas, ou seja, capazes de sobreviver ao pisoteamento, à erodibilidade e demais condições desfavoráveis do solo original, e às condições climáticas, bem como espécies resistentes ao ataque de insetos, compatíveis com outras plantas, facilmente propagáveis e mantidas com poucos insumos (MINTER \& IBAMA, 1990; ICMM, 2006; DNIT \& IPR, 2009; Highland Engineering, 2009). Além das características de adaptabilidade ao local, Heiden et al. (2006) ressaltam a importância de se considerar a origem genética e a distribuição fitogeográfica das espécies durante a seleção, evitando efeitos negativos de introduções inadequadas, tais como invasoras nativas ou exóticas. Para tanto, o uso de espécies pioneiras regionais é recomendado, embora não estritamente. Essas pioneiras provocam modificações favoráveis ao solo, facili- 
tando o estabelecimento de espécies tardias (Barbosa, 2006; Moraes et al., 2013). Seu crescimento rápido a pleno sol permite sua presença inicial na sucessão de florestas e áreas de campo. Espera-se que ao longo da sucessão, as espécies pioneiras sejam substituídas por espécies florestais (Ferretti, 2002a; Duarte \& Bueno, 2006). Nessa fase, vários autores recomendam o uso preferencial de gramíneas e outras espécies herbáceas, quando a técnica de serrapilheira não for aplicada (MINTER \& IBAMA, 1990). Uma maior proporção de gramíneas é recomendada, se for necessário realizar o controle de erosão (COFA, 2006). Dentre essas, sugerem-se espécies que forneçam uma cobertura inicial rápida, ao mesmo tempo em que não sejam persistentes, como o azevém anual (Lolium multiflorum L.) e o centeio (Secale cereale L.). Espécies nativas da família Fabaceae (leguminosas) também devem ser usadas preferencialmente, em especial aquelas reconhecidamente longevas (MINTER \& IBAMA, 1990; Tasmania, 1999; ICMM, 2006). As leguminosas apresentam diversos hábitos de vida e capacidade de enriquecimento do solo com a incorporação de nitrogênio (Nogueira et al., 2012; Melo et al., 2013). Desta forma, é possível excluir ou minimizar a necessidade de reaplicação de fertilizantes, já que as leguminosas são também faci- litadoras do desenvolvimento de espécies tardias mais sensíveis às condições ambientais (Taiz \& Zeiger, 2004). No estudo de Nogueira et al. (2012) podem ser encontrados vários exemplos de leguminosas com essas características, como o gênero Stylosanthes Sw. Ainda, a inclusão de espécies rústicas não-leguminosas, capazes de encorajar o desenvolvimento de um sub-bosque é sugerida por Carpanezzi (1998). As espécies com enraizamento profundo, por exemplo, de plantio por maniva, tolete ou estaca viva, também são indicadas (MINTER \& IBAMA, 1990; COFA, 2006; Highland Engineering, 2009; PDEP, 2012), a fim de segurar o solo e evitar o deslocamento de massas nos taludes. Espécies com tais características têm sido amplamente utilizadas em outros países (Fig. 4) (COFA, 2006; Highland Engineering, 2009; PDEP, 2012). No Brasil, a mandioca (Manihot esculenta Crantz) é um bom exemplo de espécie nativa e comumente cultivada comercialmente, que pode ser usada para tais fins (Souza \& Fialho, 2003; Oliveira, 2013). Alguns estudos apresentam espécies nativas, principalmente, para uso na recuperação de mata ciliar, como o Phyllantus sellowianus (Klotzsch) Müll. Arg. Espécies arbóreas, que necessitam de 1 a 2 m de solo, devem ser evitadas (MCA, 1998).

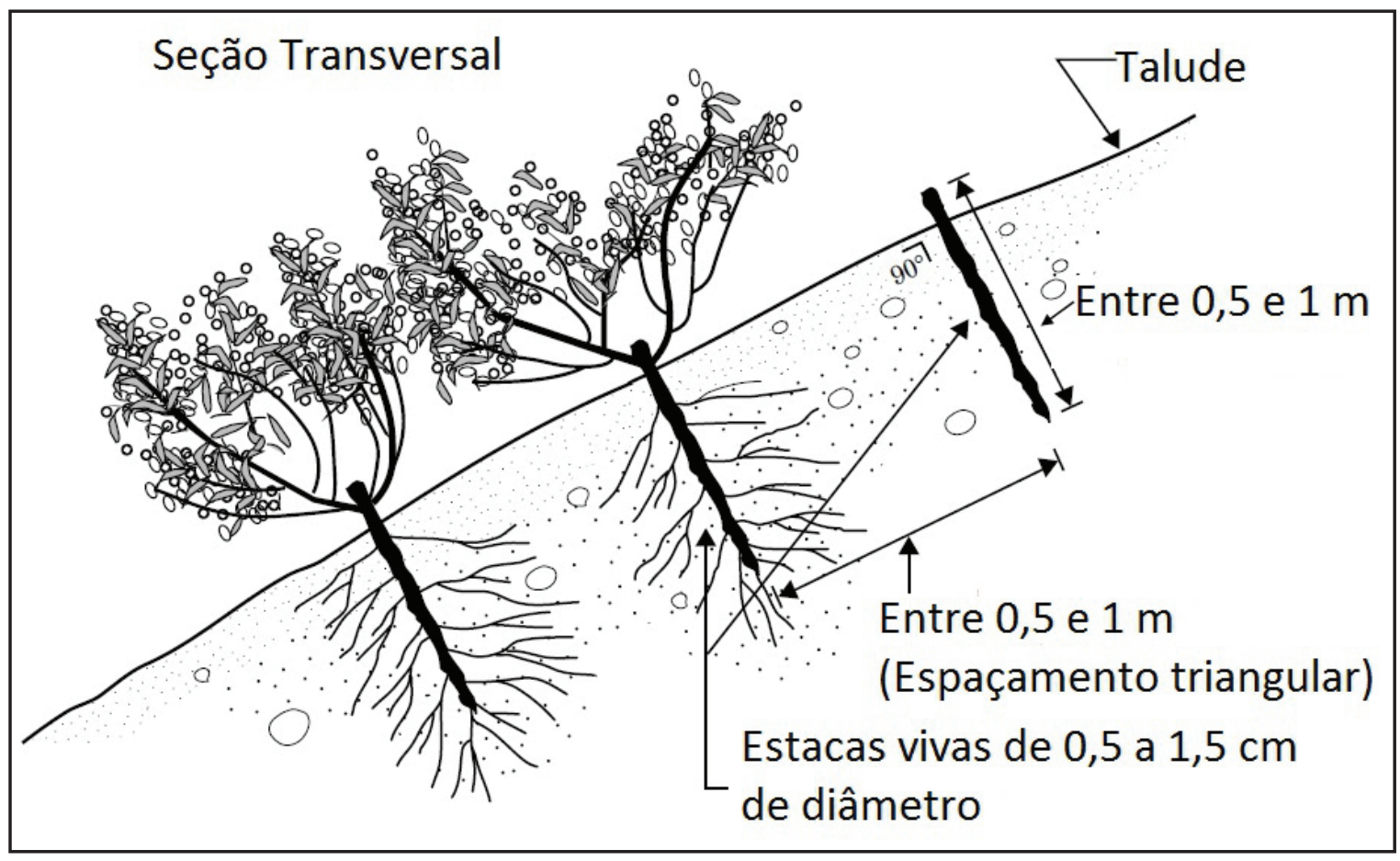

Figura 4. Plantio com estacas vivas. Seção transversal do plantio por estacas vivas em talude. Adaptado de United States Department of Agriculture (USDA) e Natural Resources Conservation Service (NRCS) (USDA \& NRCS, 1992).

Figure 4. Planting by live stake. Cross section of live stake planting technique. Adapted from United States Department of Agriculture (USDA) and Natural Resources Conservation Service (NRCS) (USDA \& NRCS,1992). 
De interesse ainda são as espécies frutíferas e/ou melíferas e as espécies com sementes aladas, que têm sua propagação facilitada por insetos, pássaros e outros animais, ou pelo vento (MINTER \& IBAMA, 1990; Carpanezzi, 1998). 0 uso destas espécies facilita o processo de recuperação da área, graças às suas características nucleadoras ou facilitadoras do recrutamento de outras espécies vegetais, assim minimizando os custos de implantação do PRAD (Reis et al., 1999).

A diversidade é essencial para o restabelecimento dos processos ecológicos e manutenção das espécies plantadas (Souza \& Batista, 2004). Estudos indicam que áreas plantadas com uma baixa diversidade de espécies não são auto-sustentáveis (Rodrigues, 1999 apud Souza \& Batista, 2004). Seguindo essa tendência e com base na restauração ecológica, o estado de São Paulo determinou requisitos mínimos legais para guiar a recuperação de áreas degradadas (Brancalion et al., 2010; Secretaria de Meio Ambiente do Governo do Estado de São Paulo - SMA-SP, 2014). Quanto à mistura de espécies, MINTER \& IBAMA (1990) sugerem o uso de no mínimo 20 espécies nativas. Entretanto, Barbosa et al. (2013) consideram cerca de 35 espécies uma quantidade de baixa diversidade florística ainda propícia para um bom resultado na restauração da área. Para formações florestais complexas, como a Floresta Estacional Semidecidual, um mínimo de 80 espécies nativas é exigido ao final do processo (SMA-SP, 2014). 0 plantio de espécies raras ou ameaçadas é também recomendado por Souza \& Batista (2004) para que seja mantida uma tendência de densidade de espécies similar à encontrada em fragmentos bem preservados (SMA-SP, 2014). 0 uso desproporcional de espécies pioneiras pode, por outro lado, resultar na morte dessas antes do estabelecimento das espécies secundárias (USP \& ESALQ, 2007).

Embora existam recomendações publicadas, há grande dificuldade, primeiramente, de estabelecer o conjunto de espécies mais propícias a serem utilizadas e, secundariamente, de adquiri-las no mercado (Souza \& Batista, 2004). No Brasil, encontram-se manuais de RAD com listas de espécies. Porém, essas contêm, geralmente, espécies nativas arbóreas, ou no caso de espécies de pequeno porte, exóticas cultivadas. Muitas das espécies citadas nos manuais desenvolvidos para os estados de São Paulo e Rio de Janeiro ocorrem também no Rio Grande do Sul, devido à distribuição meridional do Bioma Mata Atlântica (Barbosa, 2006; Moraes et al., 2013). Porém, nenhum manual específico para o RS foi identificado. Já o Bioma Pampa nesse Estado apresenta grande diversidade de espécies pioneiras altamente adaptadas ao clima e solo da região e, portanto, de interesse para a recuperação de áreas mineradas (Pillar et al., 2009). Alternativamente, é possível encontrar, através da pesquisa agropecuária, indicações de espécies de plantas de pastagem, como Paspalum plicatulum Michx. e Canavalia brasiliensis Mart. (Alvarenga et al., 1995; Carvalho et al., 2006). Os manuais elaborados por DNIT \& IPR (2009) para taludes rodoviários contêm extensas listas de espécies exóticas e também nativas com potencial de utilização em RAD, como a Mimosa pudica L. Os gêneros Ipomoae L. e Mikania Willd. são sugeridos por Reis \& Kageyama (2008) como espécies de interesse, pois como lianas (trepadeiras) predominantemente rastejantes formam rapidamente uma cobertura protetora, mesmo em taludes com grande declividade. 0 estabelecimento de diretrizes para RAD no estado de São Paulo também impactou, positivamente, o fornecimento de espécies nativas por viveiros, e a implantação favorável do PRAD (Brancalion et al., 2010).

\subsubsection{Aquisição das espécies selecionadas}

Para preservar a diversidade genética da região IBAMA \& MINTER (1990) e COFA (2006) recomendam a coleta de sementes em locais adjacentes a área a ser restaurada. Porém, para tal é necessário reconhecer as espécies, as técnicas de coleta, armazenagem e quebra de dormência das sementes. Dependendo das condições particulares, é possível estocar sementes coletadas até dois anos antes do plantio (COFA, 2006). É ainda recomendado que um estudo prévio seja realizado para garantir a viabilidade das sementes e propágulos (MINTER \& IBAMA, 1990; COFA, 2006). É importante que as taxas de germinação das espécies sejam conhecidas para estimar o número de sementes ou propágulos a serem utilizados. Quanto mais espécies nativas empregadas a partir do 
banco genético da flora regional, maior o sucesso no estabelecimento de bosques mantenedores da biodiversidade e, consequentemente, a aquisição do equilíbrio ecológico. Com referência ao local fonte de espécies, os ambientes extremamente perturbados das laterais de estradas, embora propiciem a obtenção de plantas nativas com características pioneiras, contêm muitas espécies exóticas invasoras, que devem ser evitadas durante a coleta (Tasmania, 1999, D’Antonio et al., 2011). Além disso, as espécies podem ser obtidas comercialmente de fornecedores confiáveis, se assim disponíveis (MCA, 1998). Entretanto, ainda se observa uma maioria de viveiros comercializando largamente espécies arbóreas e ornamentais sem foco prioritário em espécies apropriadas a PRAD. Neste caso, sugere-se a construção de um viveiro próprio no local, ou de forma cooperativa (MCA, 1998).

\subsubsection{Estabelecimento de uma estratégia de plantio}

Ferretti (2002b) e Reis et al. (2003) sugerem promover a restauração da vegetação através das estratégias de enriquecimento em faixas, ou ilhas de diversidade. Ferretti (2002b) ainda sugere a estratégia de "talhão facilitador", o qual potencialmente reduz os custos de execução do processo de recuperação. Essa estratégia possui um resultado lento, embora efetivo e adequado a áreas que passaram por um forte processo de degradação. De acordo com Carpanezzi (1998, p. 46) o "talhão facilitador" baseia-se no "favorecimento de um processo de sucessão secundária auto-sustentável, através de um plantio planejado, em uma área contínua (o talhão)". Existem cinco modelos baseados nesta estratégia, sendo o de melhor custo-efetivo, o chamado "Núcleo de Diversidade entre Ilhas de Pioneiras" (Ferretti, 2002b). Nesse modelo, um núcleo de diversidade é plantado na parte central da área a ser recuperada, ocupando $20 \%$ dessa. Este núcleo é composto por espécies pioneiras e espécies tardias, sem uma porcentagem determinada de espécies de cada tipo. 0 núcleo é então circundado por ilhas (módulos) de espécies pioneiras. Estas ilhas devem ter no mínimo $2.500 \mathrm{~m}^{2}$ (módulos de $50 \mathrm{x}$ $50 \mathrm{~m}$ ), com pelo menos 24 ilhas bem distribuídas na área, de modo que apenas $50 \%$ da área necessitam ser plantadas. Embora o método descrito não seja específico para áreas mineradas, as ilhas podem ser dispostas nos locais de maior prioridade, facilitando a distribuição do solo na área. Os espaços vazios irão se regenerar naturalmente.

A transposição de galharia, a serrapilheira (MINTER \& IBAMA, 1990; Reis et al., 2003; SMA -SP, 2011) e os poleiros em áreas extensas (Reis et al., 2003; SMA-SP, 2011) são ainda sugeridos como estratégias. Comparativamente aos vários modelos de "talhão facilitador", o uso destas estratégias é certamente menos oneroso (MINTER \& IBAMA, 1990; Reis et al., 2003). No entanto, essas estratégias devem ser apenas utilizadas como auxiliares a quaisquer dos modelos de talhões escolhidos. A serrapilheira é fonte de matéria orgânica, ajuda a manter a umidade do solo, é abrigo para fauna e contém muitas sementes (MINTER \& IBAMA, 1990; Correia \& Andrade, 1999; Reis et al., 2003). Além disso, devido aos diversos organismos associados, é capaz de modificar funcional e estruturalmente o solo, incorporando nutrientes (Correia \& Andrade, 1999). Sua coleta deve ser realizada por profissionais em matas nativas próximas ao sítio de mineração, em pequenas quantidades, em pontos espaçados (MINTER \& IBAMA, 1990). É importante evitar o dano a um ambiente preservado com coleta em excesso de serrapilheira, considerandose que as áreas de mineração em geral necessitam de grandes quantidades.

Os poleiros são estruturas de madeira em forma de "T", que servem de local para repouso de aves e morcegos. Esses animais, por sua vez, favorecem a introdução no solo de sementes de plantas depositadas junto as suas fezes (Reis et al., 2003). Sob o poleiro recomenda-se a colocação de um tipo de cobertura do solo, como uma camada de material vegetal fenecido (palhagem ou mulching), para propiciar sombra e umidade às sementes ali caídas e, assim, facilitar o seu desenvolvimento (Reis et al., 2003). McClanahan \& Wolfe (1993) sugerem que a técnica dos poleiros seja somente empregada em conjunto com outras técnicas, já que isoladamente não seriam suficientes para a revegetação de uma área degradada. Conforme esses autores indicam, apesar dos poleiros possibilitarem um aumento do recrutamento de espécies da flora, a germinação das espécies de estabelecimento secundário desejadas, dependerá ainda de favoráveis condições 
de solo, micro-clima, umidade, dentre outras. Além disto, tanto a serrapilheira, como os poleiros não possibilitam, como efeito ecológico, a prioritária contenção de processos erosivos em áreas de mineração (Reis et al., 2003).

Reis et al. (2003) e SMA-SP (2011) sugerem ainda a utilização de sistemas de nucleação independente da estratégia ou técnica de plantio.

\subsubsection{Técnicas para plantio}

A técnica de plantio a ser selecionada depende das características de desenvolvimento das espécies selecionadas, do solo, do maquinário disponível e de recursos financeiros. MCA (1998) e COFA (2006) sugerem que o plantio por semeadura é o de melhor custo-efetivo se as espécies coletadas possuírem altas taxas de germinação e sobrevivência, dessa forma o plantio pode ser tanto manual quanto mecanizado. 0 plantio de mudas, contudo, é mais efetivo e possibilita o controle do número e do conjunto de espécies, mas possui um custo mais elevado (COFA, 2006; DNIT \& IPR, 2009). Quanto ao plantio por leivas, DNIT \& IPR (2009) indicam que necessita de um número maior de propágulos e o coveamento do solo, embora apresente resultado imediato. 0 plantio através de estolões exige menos irrigação, porém necessita de incorporação de palha ao solo (DNIT \& IPR, 2009). Tasmania (1999) recomenda efetuar o plantio equilibrando o uso de propágulos e semeadura para um melhor resultado. Neste caso, ambos exigem irrigação até a espécie completar a pega, aproximadamente na ordem de oito litros por $\mathrm{m}^{2}$ (DNIT \& IPR, 2009). Caso opte-se pela semeadura, esta deve ser realizada quando houver previsão de chuva, reduzindo custos com irrigação (COFA, 2006). Isto também possibilita o uso de semeadeiras mecânicas (MINTER \& IBAMA, 1990; Tasmania, 1999; COFA, 2006).

A hidrossemeadura é uma técnica sugerida por diversos autores (MINTER \& IBAMA, 1990; Tasmania, 1999; COFA, 2006). Para tal é necessário executar o microcoveamento do solo. A profundidade das covas pode variar de 3 a $5 \mathrm{~cm}$. Essas são ligeiramente inclinadas para dentro e devem ser dispostas em quincôncio com distanciamento variando de 10 a $20 \mathrm{~cm}$ (Couto et al., 2010). Contudo, a hidrossemeadura é considerada de risco se não houver experiência com o seu uso (MINTER \& IBAMA, 1990; Tasmania, 1999). MINTER \& IBAMA (1990) desencorajam o uso da técnica, pois é necessário um preparo especial do solo, experiência com a dosagem das quantidades de sementes, conhecimento da inter-relação entre as espécies e domínio da máquina. Além disso, Pawelek et al. (2015) demonstram que a semeadura convencional e a hidrossemeadura não apresentam diferenças significativas na coberta das espécies, apenas no valor, sendo a hidrossemeadura substancialmente mais onerosa. Entretanto, COFA (2006) sugere que, apesar do custo, a sua aplicação pode ser necessária para o desenvolvimento da vegetação na face dos taludes.

Adicionalmente, é recomendada a cobertura do solo com aplicação de mulching, uma técnica auxiliar para minimização do processo de erosão, proteção e conservação da umidade do solo (Tasmania, 1999; ICMM, 2006; Highland Engineering, 2009). Sua aplicação aumenta a taxa de germinação, todavia verificou-se que algumas espécies possam ter seu crescimento inibido (Tasmania, 1999; Highland Engineering, 2009).

\subsection{Monitoramento}

Parte do processo de recuperação é o seu acompanhamento, o qual deve ser sensível para apontar a necessidade de ajustes ao projeto e o término do PRAD (MINTER \& IBAMA, 1990; ICMM, 2006; USEPA, 2011). Para isso, recomenda-se realizar o controle de pragas, como artrópodes e ervas ruderais invasoras (ICMM, 2006; Moraes et al., 2013). Para o monitoramento do processo de recuperação, MCA (1998) sugere o método de Análise Funcional de Ecossistema/Paisagem - conhecido como EFA (Ecosystem/Landscape Function Analysis), o qual foi apresentado originalmente por Tongway (1994) e Tongway \& Hindley (1995 apud Tongway \& Hindley, 2004).

0 método EFA foi desenvolvido para o monitoramento da paisagem, sendo largamente utilizado em áreas em processo de recuperação e, também, especificamente, pela indústria da mineração (Randall, 2004; Mahmoud et al., 2014). 0 EFA avalia a funcionalidade biogeoquímica da paisagem através de indicadores de caráter largamente vi- 
sual. Primeiramente, são realizados o mapeamento e a descrição das unidades de paisagem do local, do solo e do tipo de vegetação (Tongway \& Hindley, 2004). Os pontos de amostragem são demarcados por ferramentas de georreferenciamento, a amostragem é realizada com o auxílio de fotografias e a técnica de transecto, que deve ser repetida sempre na mesma posição para o registro das mudanças (Tongway \& Hindley, 2004). É indicado o uso de um local de referência com as mesmas técnicas usadas na área em recuperação, para o estabelecimento dos objetivos ou metas para os índices do EFA, conforme as determinações da NBR 13030 (Tongway \& Hindley, 2004). Este local deve ser próximo ao sítio em recuperação e estar em seu clímax, ou seja, ser uma paisagem estável e funcional (Tongway \& Hindley, 2004; Barbosa, 2006). Os indicadores utilizados no método apresentam baixo custo, rápida amostragem, são passíveis de aplicação em vários tipos de paisagem, preditivos e não divergem de observador para observador (Tongway \& Hindley, 2004).

Enquanto isso, apesar do monitoramento do processo ser compulsório, a falta de métodos científicos para esta etapa, em geral observada no Brasil, induz uma variação de critérios usados entre empresas e, até mesmo, escolhidos entre os analistas responsáveis pelo monitoramento ou pela avaliação do relatório técnico (Andrade et al., 2014). Alguns órgãos estaduais têm adotado o método proposto por Melo et al. (2010 apud Andrade et al., 2014) para áreas florestais. Esse método, porém, apresenta lacunas, tais como dificuldades para determinar a finalização do PRAD e um número de amostras desproporcionalmente grande, inibindo sua ampla utilização e tornando-o oneroso e inoperável (Andrade et al., 2014). Assim, o monitoramento da área pelo órgão fiscalizador é realizado, com frequência, basicamente através da avaliação dos laudos dos técnicos responsáveis pela área, acompanhado de fotografias. Essa prática, que não se restringe ao Brasil, ocorre sem o emprego de uma metodologia específica de amostragem (Randall, 2004; Corrêa, 2014). Desta forma, a avaliação tende a ser subjetiva, podendo ser, inclusive, enganosa (Randall, 2004).

\section{Considerações finais}

Vários manuais de recuperação de áreas degradadas estão disponíveis com o intuito de orientar a minimização de impactos dos diversos tipos de atividades de mineração. Sugestões técnicas de bioengenharia são encontradas para uma eficiente implantação do RAD, bem como para favorecer a diminuição dos custos da recuperação. Entretanto, é comum se verificar na literatura métodos financeiramente onerosos e por vezes ineficazes. Similarmente, são raros os métodos publicados que se valeram de estudos avaliativos de longo prazo, essenciais para a segura recomendação sobre cada estrutura construtiva e os procedimentos a serem empregados. Apesar da elevada quantidade de etapas necessárias envolvidas no manejo da área, é possível incluir alternativas construtivas, visando o reaproveitamento de materiais disponíveis no local ou na região a um custo mais baixo.

0 ajustamento do relevo é crucial para todo o processo. A inclinação dos taludes, o sistema de drenagem, a disposição do solo no local e a gradagem são muito relevantes para tanto. 0 solo deve ser manejado corretamente desde a abertura do sítio de mineração, visto que suas condições são determinantes no processo de recuperação da área.

Em uma etapa final, as características das espécies de plantas utilizadas para a revegetação determinarão o sucesso da recuperação. Os tipos de vegetais, suas interações e a forma de seu plantio devem ser avaliados de acordo com as características geoclimáticas de cada região. Embora disponíveis comercialmente, algumas plantas de uso agrícola não são suficientes para a obtenção do resultado esperado. A origem dos propágulos vegetais deve ser segura, com disponibilidade de reprodução e fornecimento comercial em escala satisfatória para as demandas. Tratamentos com substâncias químicas devem ser escolhidos estritamente com base nas deliberações normativas dos órgãos competentes de certificação e controle ambiental. Pesquisas devem ser desenvolvidas voltadas à elaboração de listas mais específicas da flora nativa e a estratégias de plantio mais econômicas para uma eficaz recuperação. Salientam-se as estratégias da chamada restauração ecológica, 
que possibilitam excelentes resultados com baixos custos através de suas características sucessionais, nucleadoras e facilitadoras.

0 monitoramento é essencial ao longo do processo de recuperação da área e principalmente na sua finalização, determinando o alcance de seus objetivos. 0 método de monitoramento escolhido deve ser único e menos subjetivo possível. Um dos mais completos e, portanto, o mais recomendado é o EFA - Análise Funcional de Ecossistema/Paisagem.

A metodologia para recuperação de uma área deve ser parte integrante do planejamento inicial da atividade, com o manejo do sítio de mineração conduzido para esse fim desde a abertura do garimpo. Essa estratégia deve ser utilizada, principalmente, para evitar impactos nos recursos hídricos, na biodiversidade, além de reduzir custos. A ênfase nessa recomendação decorre de que, ainda hoje, a gestão ambiental tem sido considerada como um gasto desnecessário e dispensável em muitos garimpos.

O conjunto de estratégias técnicas e as recomendações apresentadas neste estudo poderão guiar a compilação de termos de referência para PRAD. Sua utilização, para o melhoramento de programas de RAD por mineração de pedras preciosas e afins, contribuirá para a proteção dos ecossistemas naturais.

Agradecimentos. Ao Conselho Nacional de Desenvolvimento Científico e Tecnológico (CNPq) pela concessão da bolsa de iniciação científica PIBIC/ CNPq/FEPAM para Isis Arend da Silva. À Mariana Vinhas pelo auxílio com as ilustrações.

\section{Referências bibliográficas}

AAFRD. Alberta Agriculture, Food and Rural Development. 2001. Native Plant Revegetation Guidelines for Alberta. Alberta (CA), 67p. Disponível em: <http://aep.alberta.ca/formsmaps-services/forms/lands-forms/guidesforms-completion/documents/NativePlantRev egetationGuidelinesForAlberta-Feb-2001.pdf>. Acesso em: 8 jul. 2016.

ABNT. Associação Brasileira de Normas Técnicas. 1999. NBR 13030: elaboração e apresentação de projeto de reabilitação de áreas degradadas pela mineração. Rio de Janeiro, ABNT, 3 p.

Alvarenga, R.C., Costa, L.M., Filho, W.M. \& Regazzi, A.J. 1995. Características de Alguns Adubos Verdes de Interesse para a Conservação e Recuperação de Solos. Pesquisa Agropecuária Brasileira, 30(2): 175-185.

Andrade, G.F., Sanchez, G.F. \& Almeida, J.R. 2014. Monitoramento e Avaliação em Projetos de Recuperação de Áreas Degradadas. Revista Internacional de Ciências, 4(2): 13-26.

Araújo, E.R. 2016. Fechamento de Minas no Brasil: Aspectos legais e conseqüências sobre o meio ambiente e populações. Série Estudos e Documentos, 91. Rio de Janeiro: CETEM/MCTIC, 52p. Disponível em: <http://biblio.cetem.gov. br/handle/cetem/1964>. Acesso em: 13 dez. 2016.

Aumond, J. \& Maçaneiro, J.P. 2014. Abordagem Sistêmica e Aplicação de Rugosidades para Desencadear Propriedades Emergentes em Restauração de Solos Degradados. Ciência Florestal, 23(3): 759-770.

Australian Government Department of Resources, Energy and Tourism. 2011. A guide to leading practice sustainable development in mining. Leading Practice Sustainable Development Program for the Mining Industry Steering Committee: Creative Commons, 204p. Disponível em: <https://industry.gov.au/ resource/Documents/LPSDP/guideLPSD.pdf > . Acesso em: 4 jan. 2017.

Barbosa,L.M.(Org.).2006.Manualpararecuperação de áreas degradadas do estado de São Paulo: Matas Ciliares do Interior Paulista- Curso de capacitação e atualização em recuperação de áreas degradadas (RAD) com ênfase em matas ciliares do interior paulista. Guaratinguetá: Projeto de Políticas Públicas Ibt/FAPESP, 129 p. Disponível em: <http://www.ambiente. sp.gov.br/municipioverdeazul/files/2011/11/ ManualRecupAreas\%20Degradadas.pdf >. Acesso em: 4 jan. 2016.

Barbosa, L.M., Barbosa, J.M., Barbosa, K.C., Potomati, A., Martins, S.E., Asperti, L.M., Melo, A.C.G., Carrasco, P.G., Castanheira, S.A., Mattioli, D.S., Guedes, D.C., Junior, N.S., Machado, P., Silva, S. \& Plaza, A.P. 2013. Recuperação Florestal 
com Espécies Nativas no Estado de São Paulo: Pesquisas Apontam Mudanças Necessárias. Florestar Estatístico, 6(14): 28-34.

Batisti, V.S. \& Tatsch, A.L. 2012. O Arranjo Produtivo Local (APL) gaúcho de gemas e jóias: estruturas produtiva e comercial, arranjos institucional e educacional e relações interorganizacionais. Ensaios FEE, 33(2): 513-538.

BC. British Columbia. 2012. Revegetation Guidelines for Brownfield Sites. Appendix 4. In: Revegetation Guidelines. British Columbia, 39p. Disponível em: <http://www2.gov.bc.ca/ assets/gov/environment/plants-animals-andecosystems/fish-fish-habitat/riparian-areasregulations/rar_reveg_guidebk_sept6_2012_ final.pdf>. Acesso em: 8 jul. 2016.

Bertol, I., Mello, E.L., Cogo, N.P., Vásquez, E.V. \& González, A.P. 2006. Parâmetros relacionados com a erosão hídrica sob taxa constante da enxurrada, em diferentes métodos de preparo do solo. Revista Brasileira de Ciência do Solo, 30(4): 715-722.

BMA. Brandt Meio Ambiente. 2001. Manual de Normas e Procedimentos para Licenciamento Ambiental no Setor de Extração Mineral. Brasília. Ministério do Meio Ambiente, 132 p. Disponível em: < http://www.mma.gov.br/estruturas/ sqa_pnla/_arquivos/MANUAL_mineracao.pdf >. Acesso em: 4 jan. 2016

Brancalion, P.H.S., Rodrigues, R.R., Gandolfi, S., Kageyama, P.Y., Nave, A.G., Gandara, F.B., Barbosa, L.M. \& Tabarelli, M. 2010. Instrumentos legais podem contribuir para a restauração de florestas tropicais biodiversas. Revista Árvore, 34(3):455-470.

Brasil. Constituição da República Federativa do Brasil, 5 de outubro de 1988. Brasília, DF: Senado Federal, 1988. Palácio do Planalto: Presidência da República. Disponível em: <http://www.planalto.gov.br/ccivil_03/ constituicao/constituicaocompilado.htm>. Acesso em: 23 mai. 2016.

Brasil. Decreto n. ${ }^{\circ}$ 97.632, de 10 de abril de 1989. Dispõe sobre a regulamentação do Artigo $2^{\circ}$, inciso VIII, da Lei $\mathrm{n}^{\circ}, 6.938$, de 31 de agosto de 1981, e dá outras providências. Palácio do Planalto: Presidência da República. Disponível em: <http://www.planalto.gov.br/ccivil_03/
decreto/1980-1989/D97632.htm>. Acesso em: 23 mai. 2016.

Brito, S.N.A. 2011. Os taludes da mineração: importância e risco. Workshop II - Geotecnia e hidrogeologia aplicadas à mineração. In: CONGRESSO BRASILEIRO DE MINERAÇÃO, 14., 2011. Belo Horizonte: IBRAM. Disponível em: <http://www.ibram.org.br/ sites/1300/1382/00003540.pdf> Acesso em: 27 jul. 2017.

Carpanezzi, A.A. 1998. Espécies para recuperação ambiental. In: Galvão, A.P.M. (Coord.). Espécies não tradicionais para plantios com finalidades produtivas e ambientais. Colombo: Embrapa Florestas, p. 43-53. Disponível em: <http:// www.alice.cnptia.embrapa.br/handle/ doc/307861>. Acesso em: 17 ago. 2016.

Carvalho, P.C.F., Fisher, V., Santos, D.T., Ribeiro, A.M.L., Quadros, F.L.F, Castilhos, Z.M S., Poli, C.H.E.C., Monteiro, A.L.G., Nabinger, C., Genro, T.C.M. \& Jacques, A.V.A. 2006. Produção Animal no Bioma Campos Sulinos. Brazilian Journal of Animal Science, 35(Supl. Esp.): 156-202.

COFA. Commonwealth of Australia. 2006. Mine Rehabilitation: Leading Practice Sustainable Development Program For The Mining Industry. Australia: Camberra, 77p. Disponível em: <http://www.industry.gov.au/resource/ Programs/LPSD/Pages/LPSDhandbooks. aspx\#>. Acesso em: 22 jan. 2016.

Corrêa, P.F. 2014. Avaliação dos Planos de Recuperação de Áreas Degradadas pela Mineração de Argila no Município de Içara, Santa Catarina. Criciúma, 82p. Dissertação de Mestrado em Ciências Ambientais, Unidade Acadêmica de Humanidades, Ciências e Educação, Universidade do Extremo Sul Catarinense.

Correia, M.E.F. \& Andrade, A.G. 1999. Formação da serapilheira e ciclagem de nutrientes. In: Santos, G. A. \& Camargo, F. F.(Ed.). Fundamentos da Matéria Orgânica do Solo: Ecossistemas Tropicais e Subtropicais. 1. ed. Porto Alegre: Genesis, p. 197-226.

Couto, L., Gonçalves, W., Coelho, A.T., Paula, C.C., Garcia, R., Azevedo, R.F., Locatelli, M.V., Advíncula, T.G.L., Brunetta, J.M.F.C., Costa, C.B., Gomide, L.C. \& Motta, P.H. 2010. Técnicas de 
Bioengenharia para Revegetação de Taludes no Brasil. Boletim Técnico CBCN № 001. Viçosa: Centro Brasileiro para Conservação da Natureza e Desenvolvimento Sustentável, 119p. Disponível em: <http://www.cbcn.org.br/ arquivos/p_tecnicas_brasil_853272915.pdf>. Acesso em: 2 dez. 2016.

D’Antonio, C., Stahlheber, K. \& Molinari, N. 2011. Grasses and Forbs. In: Simberloff, D.; Remánek, M. (Ed.). 2011. Encyclopedia of Biological Invasions. London: University of California Press, Ltd., p. 280-290.

DNIT. Departamento Nacional de Infra-Estrutura de Transportes \& IPR. Instituto de Pesquisas Rodoviárias. 2005. Manual de conservação rodoviária. 2. Ed. Rio de Janeiro: IPR, 564p. Disponível em: <http://www1.dnit.gov.br/ arquivos_internet/ipr/ipr_new/manuais/ Manual \% 20 de $\% 20$ Conservacao \% 20 Rodoviaria.pdf>. Acesso em: 23 set. 2016.

DNIT. Departamento Nacional de InfraEstrutura de Transportes \& IPR. Instituto de Pesquisas Rodoviárias. 2009. Manual de vegetação rodoviária. Rio de Janeiro: IPR, v. 1, 128p. Disponível em: <http://www1. dnit.gov.br/normas/MANUAL\%20DE\%20 VEGETACAO \% 2 0RODOVIARIA \% 20 - \% 20 VOLUME\%201.pdf>. Acesso em: 23 set. 2016.

DNPM. Departamento Nacional de Produção Mineral. 2002. Portaria $n^{\circ} 12$, Norma Reguladora da Mineração, 22 de janeiro de 2002. Altera dispositivos do ANEXO I da Portaria no 237, de 18 de outubro de 2001. Diário Oficial da União, Brasília, 19 de outubro de 2001. Disponível em: <http://www.jusbrasil.com.br/ diarios/437947/pg-123-secao-1-diario-oficialda-uniao-dou-de-29-01-2002>. Acesso em: 10 ago. 2016.

Duarte, R.M.R. \& Bueno, M.S.G. 2006. Fundamentos Ecológicos Aplicados à RAD para Matas Ciliares do Interior Paulista. In: Barbosa, L. M. (Org.). Manual para recuperação de áreas degradadas do estado de São Paulo: Matas Ciliares do Interior Paulista - Curso de capacitação e atualização em recuperação de áreas degradadas (RAD) com ênfase em matas ciliares do interior paulista. Guaratinguetá: Projeto de Políticas Públicas IBT/FAPESP, 129p. Disponível em: <http:// www.ambiente.sp.gov.br/municipioverdeazul/ files / $2011 / 11 /$ ManualRecupAreas \% 20 Degradadas.pdf >. Acesso em: 4 jan. 2016.

Endruweit, L. 2010. Pelo menos cinco garimpos de minério são interditados em Salto do Jacuí. Zero Hora, Porto Alegre, 7 dez. Disponível em: <http://zh.clicrbs.com.br/rs/noticias/ noticia/2010/12/pelo-menos-cinco-garimposde-minerio-sao-interditados-em-salto-dojacui-3134378.html>. Acesso em: 29 jan. 2016. Engel, V.L. \& Parrotta, J.A. 2008. Definindo a restauração ecológica: tendências e perspectivas mundiais. In: Kageyama, P.Y., Oliveira, R.E., Moraes, L.F.D, Engel, V.L.E. \& Gandara, F.B. Restauração Ecológica de Ecossistemas Naturais. 1 ed. Botucatu: FEPAF, 340 p.

Farias, T. 2016. Obrigações de recuperar áreas degradadas por mineração têm contornos peculiares. Consultor Jurídico. Disponível em: <http://www.conjur.com.br/2016-set-10/ ambiente-juridicoobrigacao-recuperar-areasmineracao-contornos-peculiares>. Accessed on: 13 Sept. 2016.

FEPAM. Fundação Estadual de Proteção Ambiental Henrique Luis Roessler Divisão de Controle de Mineração. 2012a. Termo de Referência: Elaboração do Plano de Recuperação de Área Degradada- PRAD. 6p. Disponível em: <http://www.fepam.rs.gov.br/Licenciamento/ Area4/13.asp?Instr=sim >. Acesso em: 19 ago. 2016.

FEPAM. Fundação Estadual de Proteção Ambiental Henrique Luis Roessler Divisão de Controle de Mineração. 2012b. Termo de Referência: Relatório de Controle Ambiental e Plano de Controle Ambiental- RCA/PCA Unificados. 6p. Disponível em: <http://www.fepam.rs.gov. br/Licenciamento/Area4/13.asp?Instr=sim>. Acesso em: 23 mai. 2016.

Ferretti, A.R. 2002a. Fundamentos Ecológicos para o Planejamento da Restauração Florestal. In: Galvão, A.P.M. \& Medeiros, A.C.S. (Eds.). Restauração da Mata Atlântica em Áreas de sua Primitiva Ocorrência Natural. Colombo: Embrapa Florestas, p. 21-27.

Ferretti, A.R. 2002b. Modelos de Plantio para a Restauração. In: Galvão, A.P.M. \& Medeiros, A.C.S. (Eds.). Restauração da Mata Atlântica 
em áreas de sua primitiva ocorrência natural. Colombo: Embrapa Florestas, p. 35-43.

Heemann, R. 2005. Modelagem Estrutural $e$ Tridimensional para a Prospecção e Avaliação dos Depósitos de Ágata do Distrito Mineiro de Salto do Jacuí (RS). Porto Alegre, 175p. Tese de Doutorado, Programa de Pós-Graduação em Engenharia de Minas, Metalúrgica e de Materiais, Escola de Engenharia, Universidade Federal do Rio Grande do Sul.

Heemann, R., Strieder, A.J. \& Kellermann, C.F. 1998. Gestão de Recursos Ambientais para Área de Extração de Ágatas em Salto do Jacuí (RS). In: II SIMPÓSIO INTERNACIONAL DE QUALIDADE AMBIENTAL- GERENCIAMENTO DE RESÍDUOS E CERTIFICAÇÃO AMBIENTAL, 2., 1998, Porto Alegre.Anais de Gestão de Recursos Ambientais. Porto Alegre: PUCRS, p. 521-524.

Heemann, R., Kellermann, C.F., Strieder, A.J., Costa, J.F. \& Koppe, J.C. 1999. Erosion control system proposed for the Salto do Jacuí mine district (Brazil). In: Dniepropetrovsk- Ukraine, Pivnyak \& Singhal (eds). INTERNATIONAL SYMPOSIUM ON MINE PLANNING AND EQUIPMENT SELECTION \& MINE ENVIRONMENTAL AND ECONOMICAL ISSUES. p.473-480.

Heiden, G., Barbieri, R. \& Stumpf, E.R.T. 2006. Considerações sobre o uso de plantas ornamentais nativas. Revista Brasileira de Horticultura Ornamental, 12(1): 2-7.

Highland Engineering. 2009. Water Quality Best Management Practices for the Aggregate Mining Industry. Georgia: Atlanta, 83p. Disponível em: <http://gcaa.org/gcaaweb/bmpmanual.pdf>. Acesso em: 05 fev. 2016.

Hill, D. 1996. Guidelines for Assessing the Design, Size and Operation of Sedimentation Ponds Used in Mining. Pollution Prevention Officer. Province of Britsh Columbia, 17p.

ICMBIO. Instituto Chico Mendes de Conservação da Biodiversidade. 2014. Instrução Normativa ${ }^{\circ}$ 11. Estabelecer procedimento para elaboração, análise, aprovação e acompanhamento da execução de Projeto de Recuperação de Área Degradada ou Perturbada- PRAD. Diário Oficial da União, Brasília, DF, 12 de dez. 2014. Disponível em: <http://www.jusbrasil.com. br/diarios/82233806/dou-secao-1-12-12- 2014-pg-126>. Acesso em: 09 ago. 2016.ICMM. International Council on Mining \& Metals. 2006. Good practice guidance for mining and biodiversity. Londres: ICMM, 148p. Disponível em: <https://www.icmm.com/page/1182/ good-practice-guidance-for-mining-andbiodiversity>. Acesso em: 8 mar. 2016.

Jusbrasil. 2011. Salto do Jacuí: MPF e outros órgãos federais apuram irregularidades em lavras de pedras de ágata. Procuradoria da República no Rio Grande do Sul. Porto Alegre, 2011. Disponível em:<http://pr-rs. jusbrasil.com.br/noticias/2498776/salto-dojacui-mpf-e-outros-orgaos-federais-apuramirregularidades-em-lavras-de-pedras-deagata>. Acesso em: 29 jan. 2016.

Lanças, K.P. 2002. Subsolagem ou escarificação. Revista Cultivar Máquinas, (14). Disponível em:<http://www.grupocultivar.com.br/ artigos/subsolagem-ou-escarificacao $>$. Acesso em: 6 dez. 2016.

Luz,A.B.\& Sampaio, J.A. 2015. Desativação de Minas. Série Tecnologia Ambiental, 79. Rio de Janeiro: CETEM/MCTI, 59p. Disponível em: <http:// www.cetem.gov.br/images/palestras/2015/ mariana/sta-79.pdf>. Acesso em: 15 dez. 2016. Mahmoud, A.M.A., Hasmadi, I.M., Alias, M.S. \& Azani, A.M. 2014. Reviews of Landscape Function Analysis (LFA) Applications in Rangeland Ecoystems and its Links with Vegetation Indices (VI' s). World Applied Sciences Journal, 32(5): 986-991.

Marcus, J.J. 1997. Mining Environmental Handbook: Effects of Mining on the Environment and American Environmental Controls on Mining. Londres: Imperial College Press, 813p.

MCA. Minerals Council of Australia. 1997. Minisite Water Management Handbook. 1. ed. Sydney: MCA, 128p. Disponível em: <http://www. minerals.org.au/file_upload/files/resources/ environment/Minesite_Water_Management_ Handbook.pdf>. Acesso em: 15 fev. 2016.

MCA. Minerals Council of Australia. 1998. Mine Rehabilitation Handbook. [Camberra]: Minerals Council of Australia, 58p. Disponível em: $<$ https://miningandblasting.files.wordpress. com/2009/09/mine-rehabilitation-handbook. pdf >. Acesso em: 4 jan. 2017 
McClanahan, T.R. \& Wolfe, R.W. 1993. Accelerating Forest Succession in a Fragmented Landscape: The role of birds and perches. Conservation Biology, 7(2): 279-288.

Mechi, A. \& Sanches, D.L. 2010. Impactos ambientais da mineração no Estado de São Paulo. Estudos Avançados, 24(68): 209-220.

Melo, F.L., Simão, J.B.P., Caiado, M.A.C. \& Rangel, O.J.P. 2013. Vegetação como instrumento de proteção e recuperação de taludes. Revista Verde Agroecologia e Desenvolvimento Sustentável, 8(5): 116-124.

MINTER. Ministério do Interior \& IBAMA. Instituto Brasileiro do Meio Ambiente e dos Recursos Naturais Renováveis. 1990. Manual de recuperação de áreas degradadas pela mineração: técnicas de revegetação/IBAMA. Brasília: MINTER; IBAMA, 96p.

Moraes, L.F.D., Assumpção, J.M., Pereira, T.S. \& Luchiari, C. 2013. Manual Técnico para a Restauração de Áreas Degradadas no Estado do Rio de Janeiro. Rio de Janeiro: Jardim Botânico do Rio de Janeiro, 84p. Disponível em: < http:// ainfo.cnptia.embrapa.br/digital/bitstream/ item/73651/1/Manuall-Tecncio-para-aRestauracao-de-Areas-Degradadas-no-Estadodo-Rio-de-Janeiro.pdf >. Acesso em: 23 jan. 2017.

Moretto, R.L. 2012. Análise dos Efeitos da Vegetação na Proteção de Talude Rodoviários e Proposição de Alternativas de Revegetação na BR-386. Porto Alegre, 155p. Dissertação de Mestrado, Programa de Pós-Graduação em Engenharia Civil, Escola de Engenharia, Universidade Federal do Rio Grande do Sul.

Naruna, D.G. 2006. Uso de Vegetação Para Contenção e Combate à Erosão em Taludes. São Paulo, 64p. Trabalho de Conclusão de Curso, Graduação em Engenharia Civil, Universidade Anhembi Morumbi, São Paulo, Brasil.

Neri, A.C. \& Sánchez, L.E. 2012. Guia de boas práticas de recuperação ambiental em pedreiras e minas de calcário. São Paulo: ABGE- Associação Brasileira de Geologia de Engenharia Ambiental, 176p.

Nogueira, N.O., Oliveira, O.M., Martins, C.A.S. \& Bernardes, C.0. 2012. Utilização de leguminosas para recuperação de áreas degradadas.
Enciclopédia Biosfera, 8(14): 21-31.

Oliveira, R.A.M. 2013. Plantio consorciado de Mandioca (Manihot esculenta Crantz) e "Muvuca" de Sementes em Sistema Agroflorestal para recuperação de Áreas de Preservação Permanente Degradadas na Amazônia. In: VIII CONGRESSO DE AGROECOLOGIA, 2013. Cadernos de Agroecologia, 8(2): 1-5.

Parrotta, J.A. \& Knowles, O.H. 2008. Restauração Florestal em áreas de mineração de bauxita na Amazônia. In: Kageyama, P.Y., Oliveira, R.E., Moraes, L.F.D., Engel, V.L.E. \& Gandara, F.B. Restauração Ecológica de Ecossistemas Naturais. Botucatu: FEPAF, 340p.

Pawelek, K.A., Smith, F.S., Falk, A.D., Clayton, M.K., Haby, K.W. \& Rankin, D.W. 2015. Comparing Three Common Seeding Techniques for Pipeline Vegetation Restoration: A Case Study in South Texas. Rangelands, 37(3): 99-105.

PDEP. Pennsylvania Department of Environmental Protection. 2012. Erosion and Sediment Pollution Control Program Manual. Technical Guidance Number: 363-2134-008. PDEP, 583p. Disponível em: $\quad$ <http://www.elibrary.dep.state.pa.us/ dsweb/Get/Document-88925/363-2134-008. pdf>. Acesso em: 18 fev. 2016.

Pereira, A.R. 2001. Controle e Recuperação de Processos Erosivos com Técnicas de Bioengenharia. In: VII SIMPÓSIO NACIONAL DE CONTROLE DE EROSÃO, 2001, Goiânia.

Pillar, V.P., Muller, S.C., Castilhos, Z.M.S. \& Jacques, A.V.A. (Ed.). 2009. Campos Sulinos: conservação e uso sustentável da biodiversidade. Brasília: MMA, 403p.

Randall, J. 2004. Ecosystem Function Analysis: a tool for monitoring mine-site rehabilitation success. MESA Journal, 35: 24-27.

Reis, A. \& Kageyama, P.Y. 2008. Restauração de áreas degradadas utilizando interações interespecíficas. In: Kageyama, P.Y., Oliveira, R.E., Moraes, L.F.D, Engel, V.L.E. \& Gandara, F.B. Restauração Ecológica de Ecossistemas Naturais. 1 ed. Botucatu: FEPAF, $340 \mathrm{p}$.

Reis, A., Bechara, F.C., Espíndola, M.B., Vieira, N.K. \& Souza, L.L. 2003. Restauração de áreas degradadas: a nucleação como base para incrementar os processos sucessionais. Natureza \& Conservação, 1(1): 28-36. 
Reis, A., Zambonin, R.M. \& Nakazono, E.M. 1999. Caderno no 14: Recuperação de Áreas Florestais Degradadas Utilizando a Sucessão e as Interações Planta-Animal. In: Conselho Nacional da Reserva da Biosfera da Mata Atlântica. Série 3: Recuperação. São Paulo: Companhia de Tecnologia Ambiental, 23p. Disponível em: <http://www.rbma.org.br/ rbma/pdf/Caderno_14.pdf>. Acesso em: 26 abr. 2016.

Roberts, S., Veiga, M. \& Peiter, C. 2000. Panorama do Fechamento de Minas e da Reabilitação nas Américas: Sumário Executivo. Vancouver: IDRC-MPRI/ UBC/ CETEM, University of British Columbia, 86 p. Disponível em: <https://idl-bnc.idrc.ca/dspace/ bitstream/10625/30092/1/117614.pdf > Acesso em: 13 dez. 2016.

Sah, L., Rousseau, D.P.L., Hooijmans, C.M. \& Lens, P.N.L. 3D model for a secondary facultative pond. Ecological Modelling, v. 222, n. 9, p. 1592 1603. 2011. doi: http://dx.doi.org/10.1016/j. ecolmodel.2011.02.021

Shilton, A. \& Harrison, J. 2003. Guidelines for the Hydraulic Design of Waste Stabilisation Ponds. New Zealand: Institute of Technology and Engineering, 78p. Disponível em: <http:// www.bvsde.paho.org/bvsacd/agua2003/hidra. pdf>. Acesso em: 18 fev. 2016.

Silva, G.J. 2010. Agência Embrapa de Informação Tecnológica: Manejo do Solo. Empresa Brasileira de Pesquisa Agropecuária (EMBRAPA). Disponível em: <http://www.agencia. cnptia.embrapa.br/gestor/arroz/arvore/ CONT000fq6x5lxh02wyiv80bhgp5ps6ra6re. html>. Acesso em: 23 mar. 2016.

SMA-SP. Secretaria do Meio Ambiente do Estado de São Paulo. 2011. Restauração Ecológica: Sistemas de Nucleação. 1.ed. - São Paulo: SMA, 66p. Disponível em: <http://www.sigam. ambiente.sp.gov.br/sigam3/repositorio/222/ documentos/nucleacao.pdf $>$. Acesso em: 4 jun. 2017.

SMA-SP.Secretaria de Meio Ambiente do Governo do Estado de São Paulo. 2014. Resolução n 32, de 3 de abril de 2014. Diário Oficial do Estado de São Paulo, São Paulo, 05/04/2014. Disponível em: <http://www.ambiente.sp.gov.br/legislacao/
files/2014/04/Resolu\%C3\%A7\%C3\%A3oSMA-032-2014-a.pdf>. Acesso em: 6 jan. 2017.

Souza, F.M. \& Batista, J.L.F. 2004. Restoration of seasonal semidecidous forests in Brazil: influence of age and restoration design on Forest structure. Forest Ecology and Management, 191(1-3): 185-200.

Souza, L.S. \& Fialho, J.F. 2003. Empresa Brasileira de Pesquisa Agropecuária (EMBRAPA). Sistemas de Produção. Cultivo da Mandioca para Região do Cerrado. Disponível em: <https:// sistemasdeproducao.cnptia.embrapa.br/ FontesHTML/Mandioca/mandioca_cerrados/ sementes.htm>. Acesso em: 05 fev. 2016.

Tacey, W.H. \& Glossop, B.L. 1980. Assessment of topsoil handling techniques for rehabilitation of sites mined for bauxite within the Jarrah forest of western Australia. Journal of Applied Ecology, 17(1): 195-201.

Taiz, L. \& Zeiger, E. 2004. Fisiologia Vegetal. 3a. ed. Artmed: Porto Alegre, 719p.

Tasmania. 1999. Quarry Code of Practice June 1999. Department of Primary Industries, Water an Environment, Department of Infrastructure, Energy and Resources. 56p. Disponível em: < http://epa.tas.gov.au/documents/quarry_ code_of_practice.pdf $>$. Acesso em: 4 jun. 2017.

Tongway, D.J. \& Hindley, N.L. 2004. Landscape Function Analysis: Procedures for Monitoring and Assessing Landscapes with special reference to Minesites and Rangelands. Canberra: CSIRO Australia, 81p.

USDA. United States Department of Agriculture \& NRCS. Natural Resources Conservation Service. 1992. Chapter 18: Soil Bioengineering for Upland Slope Protection and Erosion Reduction. In: Engineering Field Handbook. United States, 61p. Disponível em: < https://directives. sc.egov.usda.gov/Open NonWebContent. aspx? content=17555. wba $>$. Acesso em: $13 \mathrm{fev}$. 2017.

USDA. United States Department of Agriculture \& USFS. United States Forest Service. 2006. Chapter 3: The Art and Science of Restoration. In: Wilderness and Backcountry Site Restoration Guide. United States. Disponível em: <http:// www.fs.fed.us / t -d / pubs / htmlpubs / htm06232815/toc.htm>. Acesso em: 8 jul. 
2016.

USEPA. United States Environmental Protection Agency. 1972. Guideline for Erosion and Sediment Control Planning and Implementation. EPA-R2-72-015: Maryland, 243p. Disponível em: $\quad<$ https://nepis.epa.gov/Exe/ZyPURL. cgi?Dockey=9100823N.txt $>$. Acesso em: 22 jan. 2016.

USEPA. United States Environmental Protection Agency. 1976. Erosion and Sediment Control: Surface Mining in the Eastern U.S. Volume 1: Planning. EPA/625/3-76/006a: Washington, 112p. Disponível em: <https://nepis.epa.gov/ Exe/ZyPURL.cgi?Dockey=300046YR.txt >. Acesso em: 11 fev. 2016.

USEPA. United States Environmental Protection Agency. 2011. EIA Technical Review Guideline: Non-Metal and Metal Mining. 1 v., part. 1. United States: EPA, 196p. Disponível em: <https://www.epa.gov/sites/production/ files/2014-04/documents/miningvol1.pdf>. Acesso em: 10 ago. 2016.

USP. Universidade de São Paulo \& ESALQ. Escola Superior de Agricultura "Luiz Queiroz". 2007. Pacto para a Restauração Ecológica da Mata Atlântica: Referencial Teórico. Piracicaba: USP/ ESALQ 145p. Disponível em: <http://www.mma.gov.br/port/conama/ processos/73C36E90/Documento_geral_ PACTO.pdf >. Acesso em: 4 jan. 2017.

Manuscrito 691 | Recebido em junho de 2017 | Aceito em dezembro de 2018 | Editora: Eduardo G. Barboza 